\title{
A comparative study of elliptic and round scramjet combustors by Improved Delayed Detached Eddy Simulation
}

\author{
Wei Yao ${ }^{1 \mathrm{a}, \mathrm{b}}$ Yueming Yuan ${ }^{2 \mathrm{a}}$ Xiaopeng $\mathrm{Li}^{3 \mathrm{c}}$ Jing Wang $^{4 \mathrm{a}}$ and Xuejun Fan ${ }^{5 \mathrm{a}, \mathrm{b}^{*}}$ \\ a. Key Laboratory of High Temperature Gas Dynamics, Institute of Mechanics, CAS, No.15 Beisihuanxi Road, \\ Beijing 100190, China \\ b. School of Engineering Science, University of Chinese Academy of Science, Beijing 100049, China \\ c. Institute of Engineering Thermophysics, CAS, No.11 Beisihuanxi Road, Beijing 100190, China
}

\begin{abstract}
To explore the combustion performance of non-rectangular type supersonic combustors, the flow and combustion characteristics in round and round-to-elliptic shape-transition (RdEST) supersonic combustors under the same configurations of flight Mach number and fuel equivalence ratio were compared based on modeling results. The fuel equivalence ratio is maintained the same as 0.8 , while two inlet Mach numbers of 2.5 and 3.0 both corresponding to a real flight Mach number of 6.5 are tested. To alleviate the strict requirements on wall-normal and -parallel grid spacing, Improved Delayed Detached Eddy Simulation (IDDES) is employed in this study to enable an automatic choice of RANS or LES mode depending on the local boundary layer thickness and turbulent viscosity. To reduce the computational cost of stiff kerosene oxidation chemistry, a total of four versions of skeletal mechanisms (respectively 48s/197r, 39s/153r, 28s/92r and current 19s/54r) have been developed based on the detailed 2815s/8217r Dagaut mechanism by using a highly efficient and reliable directed relation graph with error propagation and sensitivity analysis (DRGEPSA) method together with manual path analysis. Although the mechanism size has been significantly reduced, key kinetic properties such as adiabatic flame temperature, heat release rate, ignition delay and laminar flame speed all agree well with the original detailed mechanism. The static pressure along streamwise direction is compared with the measurement to validate the modeling results. Two key aspects are well predicted, i.e. the pressure ratio and the initial pressure rise location, indicating that the flame anchoring location and the distribution of wave structures inside the combustor are close to the actual situation. Then the aerodynamic fields are analyzed for the round and elliptic combustors to compare their flow, mixing and combustion related flow structures. The three-dimensional wave structures inside the elliptic combustor are firstly shown to reveal the influence of nonaxisymmetric cross-section on the shock train and Mach field. Especially the time evolution of the flame region is analyzed, and dominant flame modes are extracted by the aid of proper orthogonal decomposition (POD) method.
\end{abstract}

\footnotetext{
${ }^{1}$ Associate Professor, Institute of Mechanics (CAS), weiyao@imech.ac.cn, AIAA member.

${ }^{2}$ Assistant Professor, Institute of Mechanics (CAS), yuanym@imech.ac.cn, AIAA member.

${ }^{3}$ Post-doctor, Institute of Engineering Thermophysics (CAS), lixiaopeng @ iet.cn.

${ }^{4}$ Senior Engineer, Institute of Mechanics (CAS), wangjing@imech.ac.cn.

${ }^{5}$ Professor, Institute of Mechanics (CAS), xfan@imech.ac.cn, AIAA lifetime member.
}

* Corresponding author: xfan@imech.ac.cn (Xuejun Fan) 


\section{Introduction}

$\mathrm{T}_{\mathrm{in}}^{\mathrm{T}}$ Traditional scramjet combustors are usually designed to be rectangular in the cross-section to enable a tight integration of the hypersonic inlet with the planar vehicle body, which is desirable since the flow angle approaching the inlet will then be less affected by the vehicle angle-of-attack [1]. While non-rectangular combustors, such as those with axisymmetric and elliptic burner sections, also have unique advantages and are receiving increasing research interest. Compared with traditional rectangular combustors, non-rectangular combustors can avoid the influence of corners on the development of boundary layer and wave structures, improve the contact area between the transverse fuel jets and the air crossflow, and also contribute to the structure strength and weight reduction. To gain both the advantages of rectangular inlet and non-rectangular combustor, a practical approach is to combine them together by a smooth transition part, one example is the concept of REST (Rectangular-to-elliptic shape transition) used in [1-8]. To date most of the reported supersonic combustor studies are for rectangular scramjet combustors, while the flow, mixing and combustion characteristics in non-rectangular combustors are still poorly understood since still not enough research efforts have been dedicated to this area. Since 1960s, possibly the earliest experimental tests on round and elliptic supersonic combustors are reported [9, 10], however in-depth analysis on aerodynamic and combustion characteristics is a unattainable goal without the help of CFD (computational fluid dynamic) modeling at that time. Then with the advance of measurement techniques and computational techniques, visualization of the internal flow path and high-fidelity modeling become available. In recent years, the experimental and modeling studies of round [11-16] and elliptic [1-8] scramjet combustors regain new attention by some independent research entities.

The change in the cross-section shape of flowpath not only influences the injection depth but also the development of viscous boundary layer even in the upstream. In the elliptic combustor, the reduced depth in the minor axis direction is favorable for the mixing between fuel stream and air crossflow. The shape transition from the round inlet/isolator to the following elliptic burner section causes a non-equilibrium turbulent boundary layer since the shape factor (ratio of displacement thickness to momentum thickness) is changed by the local curvature [17, 18]. The resistance of boundary layer to thickening and separation due to backpressure propagate changes, and accordingly the core flow conditions change to affect the downstream fuel injection, mixing and then combustion. Especially, the elliptic section will produce complex non-axisymmetric shock waves as well as complex shock wave/turbulent boundary layer interaction (STBLI), which have been reported in [5, 7] but their 3D (threedimensional) structures have never been revealed. The axisymmetric and quasi-uniform distribution of wall heat flux facilitates the design of active-cooling system, but the non-uniform wall heat flux distribution around the elliptic combustors gives rise to great difficulty in the cooling channel layout. Tailored fuel injection designed by modeling analysis should be used for elliptic combustors to achieve maximum mixing and combustion efficiency as well as to avoid local overheating on the wall. In sum, a close observation of the effect of asymmetry on the internal flow and combustion should be made firstly to facilitate the design of non-rectangular combustors.

In this study, two typical non-rectangular combustors, in elliptic and round cross-section respectively, are modeled and validated against experimental tests. For each combustor, two cases with different crossflow Mach numbers (Mas) of 2.5 and 3.0 are studied, while the fuel equivalence ratios are kept the same. Both the crossflow conditions correspond to a flight $\mathrm{Ma}$ of 6.5 , which is simulated by a high-enthalpy flow at the isolator entrance. Supercritical kerosene is transversely injected at supersonic speeds through a group of flush-wall circular injectors circumferentially distributed upstream the cavity. Firstly the static pressure along streamwise direction is compared with the measurement to validate the modeling results. Then the flow, mixing and combustion fields are compared and analyzed for the round and elliptic combustors to reveal the combustor operation modes, flame anchoring modes and vortex structures etc. The 3D wave structures inside the elliptic combustor are firstly shown to reveal the influence of non-axisymmetric cross-section on the shock train and Mach field. Especially the time evolution of the flame region is analyzed, and dominant flame modes are extracted by the aid of proper orthogonal decomposition (POD).

\section{Numerical models}

\section{A. Turbulence model}

One of the challenges in the modeling of scramjet combustors is that the accurate modeling of Shock Wave/Turbulent Boundary Layer Interaction (SWTBLI) in the isolator and/or the forepart of the burner section, where the boundary layer may be thickened or detached by the adverse pressure gradient. Current turbulence modes are generally weak in the prediction of detached flows, especially for flows flushing through uneven walls because 
the non-equilibrium effect of boundary layer aggravates $[17,18]$. And also, due to the existence of recirculation regions, part of fuel may be entrained upstream to the isolator and reacted there. Under such circumstance, the chemistry further complicates the prediction of turbulent boundary layer. Fully resolving all the turbulent scales down to Kolmogorov scale in high-Re (Reynolds number) turbulent boundary layer is almost impossible because of the dramatic computational cost.

The concept of hybrid RANS (Reynolds-Averaged Navier-Stokes) and LES was firstly proposed by Speziale $[19,20]$ in 1997 for a varying mesh resolution in one flowfield. The approach of Limited Numerical Scales (LNS) through combining the time-averaged and spatially-filtered modeling of different flow scales was then developed by Batten et. al. [21] to accurately predict the near-wall Reynolds stress. However, for any hybrid RANS/LES approaches, one key modeling aspect is the transition between RANS and LES zones. Such transition in LNS is purely determined by the mesh resolution, rather than the local flow conditions. In the Detached Eddy Simulation (DES97) technique proposed by Spalart [22], the RANS modeling is used only for the entire boundary-layer flow (the "attached" eddies), while the LES modeling elsewhere outside the boundary layer (the "detached" eddies).

During the last decade, DES97 has been widely used to model full-scale scramjet combustors [23-28]. However, the original DES97 [22] has several requirements on the near-wall meshing, i.e. the non-dimensional normal wall distance $y^{*} \sim 0(1)$ and the wall-parallel grid spacing exceeding the thickness of boundary layer. When the wallparallel grid length becomes smaller than the boundary layer thickness, the earlier transition to LES portion will cause so-called Modeled Stress Depletion (MSD) and may lead to Grid Induced Separation (GIS) [29, 30]. However, the thickness of boundary layer and viscosity-affected sublayer (VASL) is usually unknown in prior, thus the near-wall meshing may not guarantee the aforementioned requirements. In order to avoid the requirements on wall-normal and -parallel grid spacing, Improved Delayed Detached Eddy Simulation (IDDES) ) [31, 32] is employed in this study to enable an automatic choice of RANS or LES mode depending on the local boundary layer thickness and turbulent viscosity. In IDDES, when the non-dimensional normal wall distance becomes excessively large, a so-called wall modeled LES (WMLES) branch will be activated to directly bridge the viscosity-affected sublayer (VASL) between the wall and the logarithmic layer, through acting as a semi-empirical wall function to model the wall stress in the first off-wall points in the logarithmic layer. In comparison with previous studies [16, 33,34 ] conducted by the authors' group, the application of IDDES weakens the influence of near-wall meshing on the internal flow fields.

The Favre-filtered or Favre-averaged Navier-Stokes equations including transport equations for species and absolute enthalpy are solved in a uniform framework by equally treating the turbulent viscosity in RANS and the subgrid scale (SGS) viscosity in LES. The background RANS model in the IDDES approach is one-equation Spalart-Allmaras (S-A) model [30], which is initially designed for the modeling of wall bounded flows in aerospace applications [30], and shows good predictive accuracy for boundary layer with adverse pressure gradient. One additional variable known as modified turbulent kinematic viscosity is solved to obtain the real turbulent viscosity. S-A model contains a wall destruction term to reduce the turbulent viscosity of laminar sub-layer and logarithmic sub-layer, providing a smooth transition from turbulent to laminar status when approaching the wall [35]. Gradient diffusion models with constant Prandtl (Pr) and Schmidt (Sc) numbers of 1.0 are used to account for the heat and mass diffusions due to unresolved turbulent eddies. Our tests show that the variation of $\operatorname{Pr}$ and $S c$, e.g. from 0.5 to 1.5 , has a weak influence on the combustion efficiency and the flame stabilization mode, suggesting that the macrostirring between the jet and the crossflow determines more the heat release distribution, implying more efforts should be put to improve the jet penetration height rather than the near-field mixing around the jet porthole(s).

\section{B. Kerosene mechanism reduction and turbulent combustion modeling}

The most computationally expensive part in the hydrocarbon fueled combustor modeling is possibly the chemistry solving because of the ultra-large mechanisms and the chemical stiffness. The species number and reaction steps increase with the molecule size roughly in an exponential trend [36]. Typically, the detailed mechanisms for small-molecule fuels $\left(\mathrm{C}_{1^{-}}\right.$and $\mathrm{C}_{2^{-}}$based) consist of less than one hundred species, while largemolecule Jet fuels $\left(\mathrm{C}_{>10^{-}}\right.$based) consist of hundreds of or even thousands of species. For this reason, current supersonic combustion modelings are mostly based on hydrogen fuel [24,37-48] and only a small portion of them are based on small-molecule hydrocarbon fuels (.g. ethylene [49,50], methane [51, 52] and acetone [53]). Even few are based on kerosene [54-57], and the complex chemistry is simply simulated by using global or semi-kinetic mechanisms [58-61]. Although some detailed mechanisms for kerosene type fuels (e.g. Jet-A, JP-8) have been developed [62-68], they are simply too large for 3D modeling without substantial reduction [36]. Actually the computation using such detailed kerosene mechanisms is time consuming even for 0-D (zero-dimensional) modelings. The size of those detailed mechanism is still growing with time due to new chemical kinetics are continuously discovered [36]. Since the computational cost is scaled with the square of specie number [36], special efforts are devoted to reduce the kerosene combustion mechanism(s) with thousands of species into those with 
species number below 50, which is a compromise between that affordable by high-resolution modeling and that can approximate the kinetic properties. In addition to the large size, the dramatic differences in chemical time scales give rise to severe chemical stiffness. The oxidation of fast depleting radicals (e.g. $\mathrm{H}, \mathrm{OH}$ and $\mathrm{CH}$ ) in the detailed mechanisms has much shorter reaction process than the pyrolysis of large fuel molecules $\left(\mathrm{e} . \mathrm{g} \cdot \mathrm{C}_{10} \mathrm{H}_{22}\right) \cdot \mathrm{The}$ elimination of unimportant intermediate species and simplification of interconnected reaction chains can also effectively reduce the stiffness of detailed mechanisms. In the serial studies conducted by the authors' group, the detailed kerosene mechanism proposed by Dagaut et al. [62] is reduced under the typical working condition range of scramjet combustors, i.e. equivalence ratio of 0.6-1.4, static pressure of 0.5-3.0 bar, and static temperature of 3003000 K. Till now, four versions of skeletal mechanisms, respectively 48s/197r [34], 39s/153r [16, 33], 28s/92r [69] and current $19 \mathrm{~s} / 54 \mathrm{r}$ [70], have been developed from the original 2815s/8217r mechanism [62] by using a highly efficient and reliable directed relation graph with error propagation and sensitivity analysis (DRGEPSA) method [71] together with manual path analysis. Although the mechanism size has been significantly reduced, the key kinetic properties such as adiabatic flame temperature, heat release rate, ignition delay and laminar flame speed agree well with the original detailed mechanism, as shown in Figure 1. In this study, the latest version of reduced RP-3 mechanism with species number of 19 and reaction number of 54 will be used to predict the combustion chemistry of PR-3.

The mechanism reduction is actually a multi-disciplinary problem, which involves researchers far beyond from the chemistry community. In addition to the convectional reduction in species and reaction number for large-scale mechanisms, there are some other optimization computational techniques, such as tabulation [72-77] and Artificial Neural Network (ANN) [78-81] to reduce the computation cost in the direct integration of the stiff chemistry system. In this study, In Situ Adaptive Tabulation (ISAT) method [72, 73] is adopted to speed up the solving of stiff chemistry system. After several interactions, the size of ISAT table becomes stable and its content is constantly synchronized with the chemistry fields. In our case calculations, the direct integration in cells up to $98 \%$ can be avoided, and the chemistry solving time in each time step is reduced to approximately only $30 \%$ of that without using ISAT. Some other techniques, such as the representation of chemical kinetics by ANN has also been implemented by the authors' group. However, the insufficient training of ANN may lead to spurious results for large-scale yet high-stiff mechanisms. The current ISAT is generally more reliable for the simulation of complex kerosene kinetics, though with larger memorv requirement
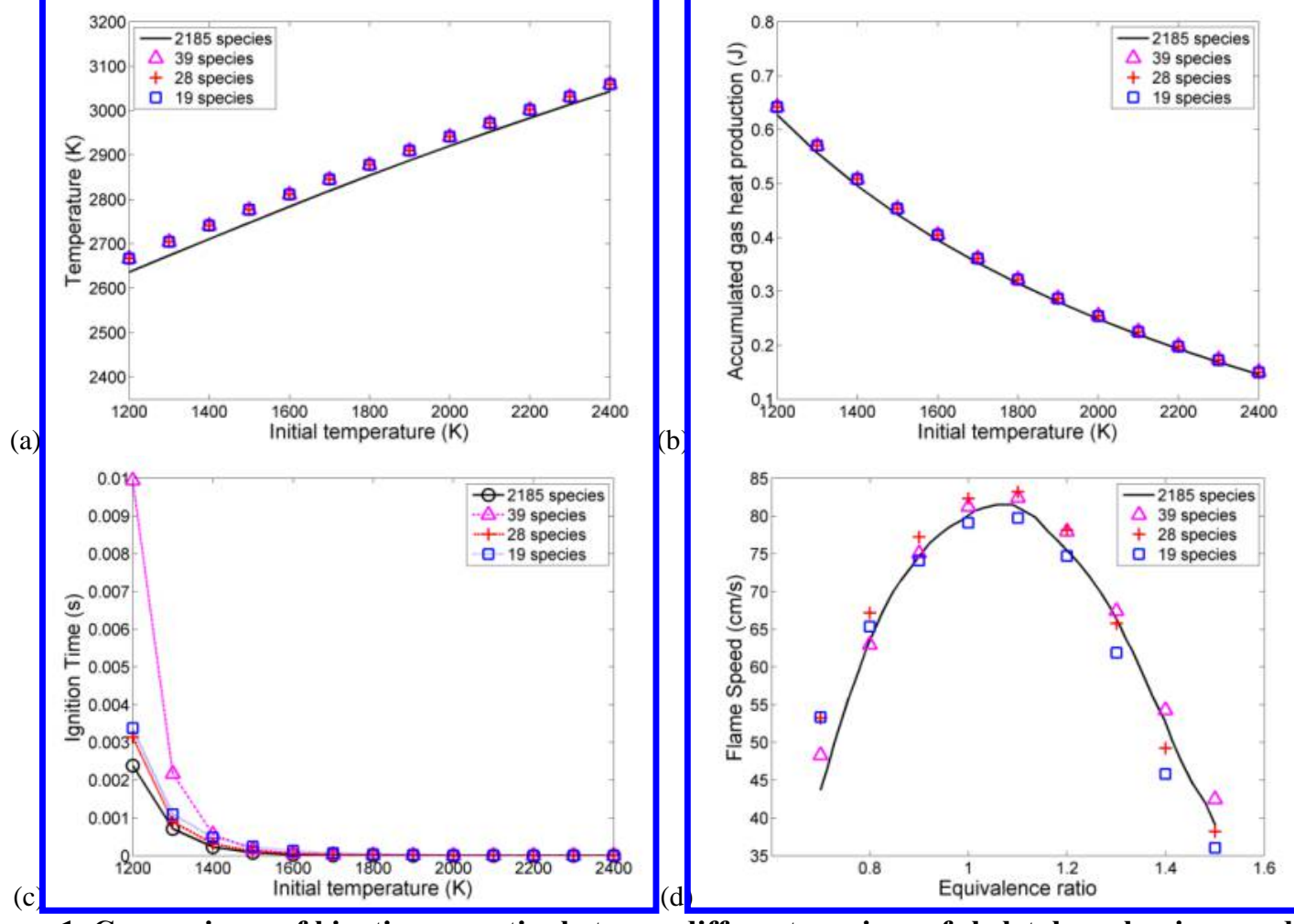

Figure 1. Comparisons of kinetic properties between different versions of skeletal mechanisms and the original detailed mechanism (2185s/8217r) for (a) flame temperature, (b) total heat release, (c) ignition delay and (d) laminar flame speed

4

American Institute of Aeronautics and Astronautics 
The nature of EBU (Eddy Break Up) [82], EDM (Eddy Dissipation Model) [83], EDC (Eddy Dissipation Concept) model $[84,85]$ and PaSR (Partially Stirred Reactor) model $[86,87]$ are essentially the same, i.e. assuming that reactions only occur in a well-mixed small-scale eddies (in comparable with Kolmogorov size), named fine structures, and thus the chemical reactions are constrained by the break-up/dissipation rate of large-scale eddies into small-scale eddies. The EBU and EDM assume an infinite fast chemistry, while the finite-rate chemistry is taken into account in the EDC and PaSR model. The PaSR model considers that the micro-mixing is in competition with the reaction progress rate, and the final reaction rate $\omega_{\mathrm{t}}$ is mutually determined by the characteristic time scales of chemical reactions $\tau_{\mathrm{c}}$ and turbulent micro-mixing $\tau_{\mathrm{mix}}$,

$$
\omega_{t}=\omega_{l} \frac{\tau_{c}}{\tau_{c}+\tau_{m i x}}
$$

where $\omega_{l}$ is the reaction rate over the current integration time step, $\tau_{\text {mix }}$ is the micro-mixing time scale, and $\mathrm{C}_{\mathrm{mix}}=1$ 1.0. In PaSR, the micro-mixing time scale $\tau_{\text {mix }}$ is on the same order of magnitude of Kolmogorov time scale $\tau_{\mathrm{k}}, \tau_{\text {mix }}=\mathrm{C}_{\text {mix }}\left(\frac{v_{\text {eff }}}{\epsilon}\right)^{1 / 2} \sim 0\left(\tau_{\mathrm{k}}\right)$ with $\mathrm{C}_{\text {mix }}=1.0$. In the S-A based DES, the SGS turbulent kinetic energy $\mathrm{k}_{\text {sgs }}$ and it dissipation rate $\epsilon$ are estimated from their relationships with SGS eddy viscosity $v_{t}$, i.e. $\mathrm{k}_{s g s}=\left(v_{t} /\left(c_{k} d_{D D E S}\right)\right)^{2}$ and $\epsilon=2 v_{e f f}\left|S_{i j}\right|^{2}$, with $c_{k}=0.07$ and $\mathrm{S}_{\mathrm{ij}}$ is the strain rate. Usually, the characteristic chemical time scale is calculated as the reciprocal of elements of Jacobian matrix $\left(\partial \omega_{i} / \partial c_{i}\right)^{-1}$, whose results of $\tau_{c}$ are essentially the same with $c_{i} / \omega_{i}\left(c_{i}\right.$ - molar concentration, $\omega_{i}$ - reaction rate of species $\left.i\right)$ [88]. Because different elementary reactions can have extremely different chemical time scales varying by orders of magnitude, causing stiff problem in solving the chemistry and on the other side making difficulty in determining an approximate overall chemical time scale. In this study, the overall chemical time scale is estimated as the summation ratio of species concentrations to reaction rates $\tau_{\mathrm{c}}=\sum c_{i} / \sum \omega_{i}$.

The ensemble "turbulent" reaction rate is constrained by the creation of fine structures in both EDC and PaSR. There are two extremes in the physical pictures of EDC and PaSR. 1) The micro-mixing is extremely fast such that $\tau_{\mathrm{mix}} \rightarrow 0$, the well-mixed fine structures expand to fill the whole cell volume. Then the ensemble turbulent reaction rate is purely determined by the chemical reaction rate, i.e. both the EDC and PaSR approach the quasi-laminar (QL) combustion model assuming a perfectly stirred cell mixture. 2) The micro-mixing due to turbulent stirring is extremely slow such that $\tau_{\mathrm{mix}, \mathrm{t}} \rightarrow \infty$, which occurs in flows of weak turbulence. The weak turbulence implies that the energy dissipation rate $\epsilon$ from large scale $l_{0} \epsilon \sim u\left(l_{0}\right)^{3} / l_{0}$ is small, and the flow approaches laminar status. Note that although the turbulent micro-mixing rate is extremely slow, it does not mean that the overall micro-mixing rate is a trivial quantity, become the micro-mixing due to molecular diffusion may become dominant as $\tau_{\text {mix, }} \ll$ $\tau_{\mathrm{mix}, \mathrm{t}}$ and $\tau_{\mathrm{mix}}=\tau_{\mathrm{mix}, \mathrm{t}}+\tau_{\mathrm{mix}, \mathrm{l}}$, where $\tau_{\mathrm{mix}, \mathrm{l}}$ is the laminar diffusion time scale. Under such circumstance, the fine structures still exist in the cell volume due to laminar diffusion. From this point of view, laminar diffusion should be included in calculation of the time and length scale of the fine structures, so that the EDC and PaSR can be applied to weak turbulent flows. In PaSR, the calculation of $\tau_{\text {mix }}$ is slightly different than the calculation of Kolmogorov time scale $\tau_{\mathrm{k}}$ by replacing the kinetic viscosity $v$ with effective kinetic viscosity $v_{\text {eff }}$, thus the effect of laminar diffusion has been included. But in EDC, there is no such treatment, thus in weak turbulent flows the fine structure volume defined by turbulent dissipation rate $\epsilon$ shrinks to nearly zero.

In the above physical pictures, the fine structures in each cell volume are isolated and their transport due to convection is not considered. Actually, due to the irreversibility of eddy dissipation process, once a fine structure is created it will not vanish and will be entrained and convected downstream. Thus the volume fraction of fine structures in one cell contains two parts, one is convected from the outer cells, and the other is created inside itself during current time step. The transport equation of the volume fraction of fine structures $\gamma^{*}$ is proposed as,

$$
\frac{\partial\left(\rho \gamma^{*}\right)}{\partial t}+\nabla \cdot\left(\rho \vec{u} \gamma^{*}\right)=\omega_{\gamma^{*}}
$$

where the source term $\omega_{\gamma^{*}}$ is the formation rate of fine structures and can be modeled by the break-up/dissipation rate proposed for EDM model [83]. $\omega_{\gamma^{*}}=C_{E B U} \rho \sqrt{\widetilde{Y}^{\pi 2}}(\epsilon / k)$, where the model constant $C_{E B U}=0.35 \sim 0.4$. The root mean square of species concentration fluctuation $\widetilde{Y^{\prime 2}}$ is calculated as,

$$
\widetilde{Y^{\prime \prime 2}}=\min \left(Y_{F}, \frac{Y_{o}}{\gamma_{0}}, \frac{B Y_{P}}{1+\gamma_{0}}\right)
$$

where the model constant $B=4.5, \gamma_{0}$ is the fuel-oxidizer equivalence ratio, $Y_{F}, Y_{o}$ and $Y_{P}$ are respectively the mass fraction of representative fuel, oxidizer and product species. The volume fraction has a maximum of 1 , thus the 
value of $\gamma^{*}$ should be limited during the equation solving. The chemistry is advanced in each fine structure by using current time step. Actually, in consideration of the finite turbulent flame speed, the chemical reaction time is inhomogeneous inside the fine structures, i.e. gradually decreasing from the initial micro-mixing layer to the outer layers. An accurate estimation of the chemical reaction time is impossible because the shape evolution of fine structures is unknown, but this effect can be accounted for by using a semi-empirical constant $\mathrm{C}_{\Delta t}(\leqslant 1)$ multiplied to the current time step. The new turbulent reaction rate defined is thus given as, $\omega_{t}=\omega^{*} r^{*}$, with $\omega^{*}$ is the reaction rate integrated over the volume averaged reaction time $\mathrm{C}_{\Delta t} \Delta t$. In this study, the turbulence-chemistry interaction is still accounted for by the original PaSR model [86, 87], and results from developed dynamic EDC model will be compared in a future study.

\section{Case setup}

To explore the combustion and thrust performance of non-rectangular type supersonic combustors, the flow and combustion characteristics of round and round-to-elliptic shape-transition (RdEST) supersonic combustors (schematically shown in Figure 2) under the same configuration of flight $\mathrm{Ma}$ (Mach number) and fuel equivalence ratio were compared based on experimental measurements and corresponding modeling. Both the round and elliptic combustors are tested in a continuous-flow supersonic combustion test facility. The test facility can simulate flight Mach numbers of 4-7 and altitudes of 16-28 km. The vitiated air heater provides high-enthalpy incoming flow with total temperatures of $900-2000 \mathrm{~K}$ and flow rates of $2.5-5.0 \mathrm{~kg} / \mathrm{s}$ through burning hydrogen with oxygen replenishment in air stream. Liquid kerosene heated to supercritical status by an electric ceramic heater is delivered to the test article. The scramjet combustors are composed of three sections: a 600-mm-long isolator section with a slight $0.7^{\circ}$ divergence angle, an 800 -mmm-long burner section, and a 600 -mm-long expander section with a large $4^{\circ}$ divergence angle. The burner section is changeable between the round and elliptic modules, while the isolator and expander sections are shared for the two combustors, as shown in Figure 2. The elliptic burner section has the same cross-section area with the round one along the streamwise distance. There are two circumvented cavities assembled in tandem in the burner section for the purpose of flame anchoring and possibly re-ignition Both the cavities have an depth of $15 \mathrm{~mm}$ and a length-depth ratio of 7 , thus are classified as open cavities where the shear-layer reattachment takes place near the aft wall. The aft walls of the cavities are at an angle of $45^{\circ}$ relative to the cavity floor. For the round section, the ignition hydrogen and supercritical kerosene are respectively injected from eighteen 1-mmdiameter and eight 2-mm-diameter evenly spaced circular injectors. For the elliptic section, the number of injection portholes are reduced to 16 and 6 respectively, with no injection on the clip plane through the long axis. The diameter of kerosene portholes increases to $2.5 \mathrm{~mm}$ to accommodate the reduction in number. Static pressure is measured by Motorola MPX2200 pressure transducers along the inner wall of the combustor assembly all with 50 mm intervals.

The four tests as summarized in Table 1 with incoming air crossflow corresponding to a flight Ma of 6.5 are conducted. The incoming vitiated air, which is supplied by burning hydrogen in air with oxygen replenishment at unity equivalence ratio, has a raised stagnation temperature of around $1600 \mathrm{~K}$ and a mass flow rate of around 3.6 $\mathrm{kg} / \mathrm{s}$ at the isolator entrance. The compositions of vitiated air are $\mathrm{N}_{2}$ in $60.5 \%$ mole fraction, $\mathrm{O}_{2}$ in $21.7 \%$ and $\mathrm{H}_{2} \mathrm{O}$ in $17.8 \%$. The global fuel equivalence ratio maintains 0.8 (symbolized by $\Phi$ ) for all the cases, while the entrance Ma changes from 2.5 to 3.0 to examine the performance of combustors under different flight conditions. The kerosene is pre-heated to above its critical temperature of $630 \mathrm{~K}$ to save the gasification time and enhance its mixing with the vitiated air. In the tests, kerosene is injected immediately following the shut off of ignition hydrogen. The combustor is not protected by any recirculating water-cooling system, i.e. the steel combustor walls are exposed directly to the hot combustion gas. No significant damage to the wall surface after the test duration of approximately $27 \mathrm{~s}$, indicating that the wall temperature is still within the thermal limit $(\sim 1300 \mathrm{~K})$ of the wall material. The time sequences of test procedures (e.g. vitiated air heating and injection, fuel injection, hydrogen ignition and finial flush washing) and data acquisition are all automatically controlled by a computer system. 


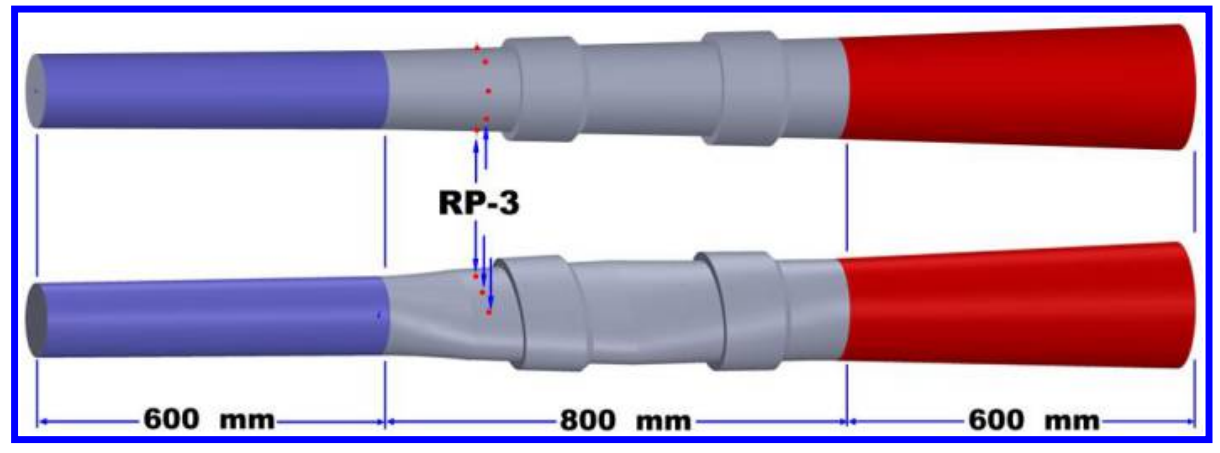

Figure 2. Schematic of the (up) round and (down) elliptic scramjet combustors consisting of isolator, burner and expander sections

Table 1. Test configurations

\begin{tabular}{|c|c|c|c|c|c|c|c|c|c|}
\hline \multicolumn{4}{|c|}{ Vitiated air crossflow } & \multicolumn{4}{|c|}{ Kerosene injection } & \multirow{2}{*}{$\begin{array}{l}\text { Injector } \\
\text { Numbers }\end{array}$} & \multirow{2}{*}{$\begin{array}{l}\text { Combustor } \\
\text { Burner shape }\end{array}$} \\
\hline $\mathrm{P}_{0}$ & $\mathrm{~T}_{0}$ & $\mathrm{Q}_{\text {air }}$ & $\mathrm{Ma}$ & $\mathrm{P}_{\mathrm{f}}$ & $\mathrm{T}_{\mathrm{f}}$ & $\mathrm{Q}_{\text {fuel }}$ & $\Phi$ & & \\
\hline $\mathrm{MPa}$ & $\mathrm{K}$ & $\mathrm{g} / \mathrm{s}$ & & $\mathrm{MPa}$ & $\mathrm{K}$ & $\mathrm{g} / \mathrm{s}$ & & & \\
\hline 0.85 & 1615.5 & 3575.9 & & 5.52 & 789 & 212.8 & 0.8 & 6 & elliptic \\
\hline 0.85 & 1611.2 & 3602.7 & 2.5 & 3.77 & 788 & 212.6 & 0.8 & 8 & round \\
\hline 13.66 & 1581.7 & 3578.9 & 3.0 & 5.77 & 784 & 218.1 & 0.8 & 6 & elliptic \\
\hline 13.66 & 1661.1 & 3557.1 & & 5.74 & 792 & 214.9 & 0.8 & 8 & round \\
\hline
\end{tabular}

\section{AstroFoam degenerated from OpenFOAM and other numerical details}

The modeling is performed by the compressible reacting flow solver AstroFoam, which is developed on the basis of the compressible flow solver rhoCentralFoam distributed with OpenFOAM V3.0.1 CFD package [89] mainly through adding the features of multi-species transport and multi-component reaction. AstroFoam together with the original rhoCentralFoam solver was firstly validated for various frozen flows, including the canonical shock tube problem, forward step flow, hypersonic flow over a boconic and supersonic jets [90-93]. The solver is then applied for various scramjet combustor cases $[33,69]$ to examine its accuracy and robustness in the engineering modeling of supersonic combustion.

The computational domain contains the isolator, burner and expander sections in their full size. Due to the bilateral symmetry of the combustors, one-eighth splitted domain (in the radial direction) for the round combustor and quarterly splitted domain for the elliptic combustor is modeled with symmetrical boundary condition applied to the splitting planes. The unstructured mesh is generated using the Cartesian CutCell method, which uses a patch independent volume meshing approach with surface mesh automatically created from the boundary of volume mesh. The Cartesian CutCell method can produce high-quality uniform hexahedral grid cells for most internal volume of the computational domain, while tetrahedron, wedge or pyramid cells are filled only in large-curvature regions e.g. near the borders or corners. The boundaries cut through the Cartesian grid volumes and CutCell method is classified as immersed boundary (IB) based method. The whole domain is meshed firstly with uniform $1 \mathrm{~mm}$ cells, which are then adaptively refined based on the local curvature and size function. Away from the boundary layer, the minimum cell size is $0.125 \mathrm{~mm}$, which is distributed around the fuel injectors. Inflation layer consisting of 23 prism layers are laid on the wall boundaries. The initial prism layer height closest to the wall is $5 \mu \mathrm{m}$, which corresponds to a nondimensional cell size $y^{*}<1$ on all the wall surfaces for the examined combustor flows. The inflation layer has an averaged thickness of $2 \mathrm{~mm}$, with the last prism located in the logarithmic layer. The total cell number in the splitted combustor domain is 10 million for the round combustor and 27.43 million for the elliptic combustor. In the following analysis, the coordinate origin locates at the lower left corner of the isolator inlet plane viewed from outside, with $\mathrm{X}, \mathrm{Y}$ and $\mathrm{Z}$ respectively represent the streamwise, height and spanwise directions.

Fixed pressure, temperature and velocity on the isolator inlet and the fuel inlets are set according to those listed in Table 1. Principle of extended corresponding states (ECS) for RP-3 kerosene[94] is used to calculate the fuel injection velocity from the mass flow rate since the compressibility of supercritical RP-3 cannot be described by the ideal gas equation. RANS type turbulent inlet boundary condition is specified on the isolator inlet by fixing a turbulence viscosity corresponding to $v_{t} / v=1$. The molecular viscosity $v$ is calculated based on Sutherland 
formula, then constant $\operatorname{Pr}$ and $S c$ with the value of 1.0 are applied for the calculation of thermal and mass diffusion coefficients. Open boundary condition is applied to the expander outlet, where zero gradient is used for outflow and ambient flow conditions for temperature and gas composition are specified should backflow occur. Non-slip boundary condition is applied on the combustor walls. Inner wall temperature along the streamwsie direction is specified as a linear function varying from $500 \mathrm{~K}$ at the isolator entrance to $1200 \mathrm{~K}$ at the expander outlet.

The computations are performed in parallel at national supercomputer center in Tianjin (TH-1) using $240 \mathrm{CPU}$ cores. Each modeling case costs about 150,000 CPU hours to ensure a 3 flush through times (FTTs) over the whole combustor flowpath for data sampling and statistics, before the 3 FTTs to reach the quasi-steady flow status.

\section{Results and discussion}

\section{A. Comparison of aerodynamic fields}

Firstly a grid sensitivity analysis is conducted for the elliptic combustor case operated at $\mathrm{Ma}=3.0$. The mesh with 27.43 million cells and a maximum cell size of $1 \mathrm{~mm}$ is used as the comparison base. Then the mesh in the whole domain is refined to reach 46.17 million cells and a maximum cell size of $0.65 \mathrm{~mm}$. From the comparision in Figure 3 , the discrepancy between the predictions by the two mesh sets is generally small and the maximum error is within $3 \%$. The two predictions are almost identical in most of the flowpath excepet around the downsteam cavity. This is because the intense combustion reactions around the downstream cavity lead to more complex flow structures, which may require a finer mesh to fully capture. Since the heat release there occurs farther downstream of the peak pressure rise location, thus can be considered to have a small influence on the peak pressure rise ratio. The focus of current study is to evaluate the overall combustor performance and reveal the main flow structures, thus the intricate flow structures and their interactions with combustion reacions are remained for the future study. For transverse jet flames, the jet penetration may have an important impact on the overall jet mixing and then pressure rise. Thus the local mesh around the jet portholes is further refined to reach a minimum size of $80 \mu \mathrm{m}$ and a total cell number of 49.16 million. However from the comparison, it seems that the pressure profile is insensitive to the refirement. Thus in the following case calculations, the meshes with a maximum size of $1 \mathrm{~mm}$ will be used to alleviate the huge computational costs.

Figure 4 compares the measured and predicted static pressure along the streamwise direction. Three data groups measured at different times during the quasi-steady period are plotted. The prediction has been averaged over 3 FTTs. The data were collected on the clip plane through the long axis for the elliptic combustor. The predictions seem to be better for the $\mathrm{Ma}=3.0$ case, where both the pressure rise ratio and the initial pressure rise location are well predicted, indicating that the flame anchoring location and the distribution of wave structures inside the combustor are close to the actual situation. For the $M a=2.5$ cases, the pressure rise ratios are well predicted, but the predicted initial pressure rise locations, which correspond to the foot of first oblique shock wave, shift upstream for about 10 $\mathrm{cm}$. The location of first shock wave is mainly influenced by the back pressure and the boundary layer condition. Since the predicted pressure rise ratio is in accordance with the experimental data, the disagreement can only be attributed to the uncertainty in boundary layer modeling. As observed, the shifting distance of shock train is roughly proportional to the boundary layer displacement thickness, which then increases with the flow Ma and decreases with the flow Re (Reynolds number). At a lower entrance Ma (e.g. 2.5), Re decreases as well (the same flow flux but higher static temperature), thus their effects counteract somewhat. From the measurements, Note there are some factors that may not be taken into account in current modelings, for example the wall roughness and the inflow turbulence, which influence the initial pressure rise location through changing the boundary layer thickness. Further continuous studies are needed to examine the influencing factor of initial shock train location.

Figure 5-8 respectively show the instantaneous fields of Mach number, static temperature, numerical shadowgraph and vorticity magnitude, which are compared for the elliptic and round combustor at different entrance Ma. The sonic line in Figure 5 indicates that all combustors run in scramjet mode. The subsonic regions on the shown clip planes are obviously larger for round combustors. As Ma changes from 2.5 to 3.0, the initial location of shock train remains almost the same for the elliptic combustor, but it slides downstream for around 1D (D is the entrance diameter) for the round combustor. Since the downstream mixing and combustion efficiency are strongly influenced by the movement of shock train, the elliptic combustor is supposed to have better combustion stability. The change of burner section from round to elliptic cross-section is to increase the mixing of jet with air crossflow, by using the short axis. However, from Figure 5 it seems that the jet penetration depth decreases for the elliptic burner cases. The jet momentum flux ratio $(J)$ of round to elliptic cases is around 1.1 for each jet porthole, but this does explains the obviously higher jet penetration height denoted by height of Mach disk $H$, because $H / D \sim f(J)$ [95] and D is larger for the elliptic cases. The only explanation is possibly that the momentum flux of the crossflow 
is significantly changed by the shape change in cross-section, as indicated by the wide distribution of subsonic regions in the round combustor cases.

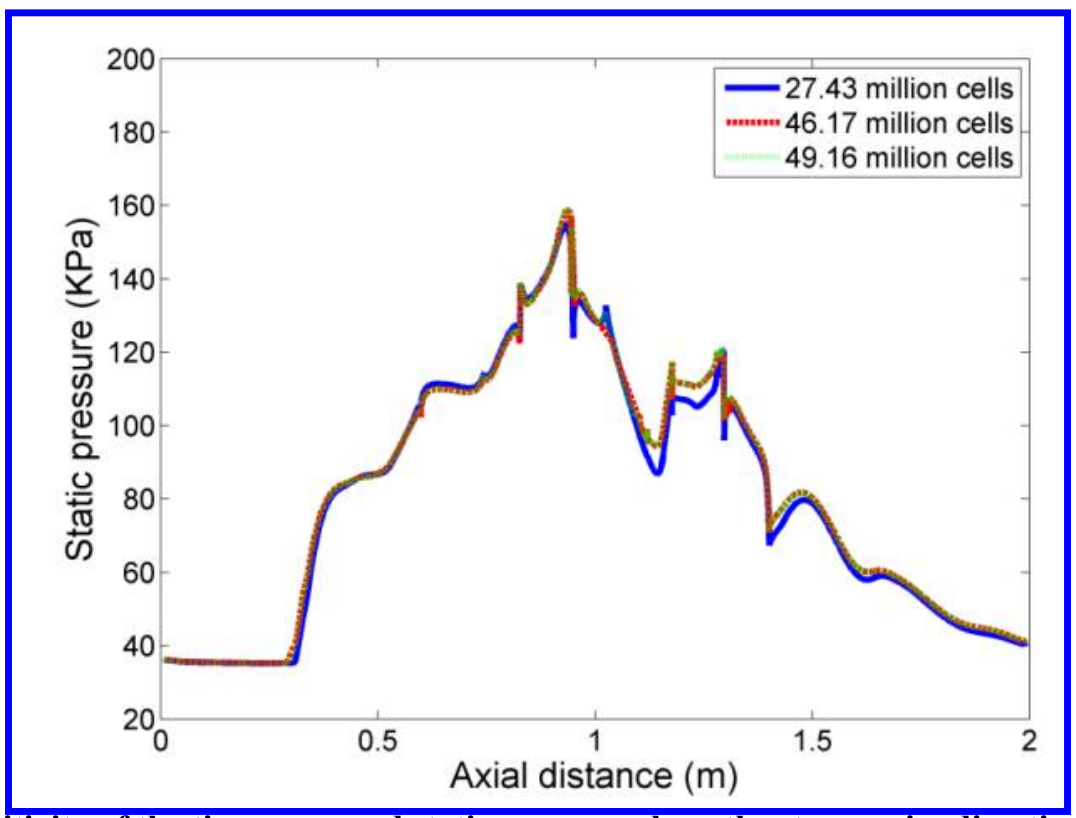

Figure 3. Grid sensitivity of the time-averaged static pressure along the streamwise direction for elliptic

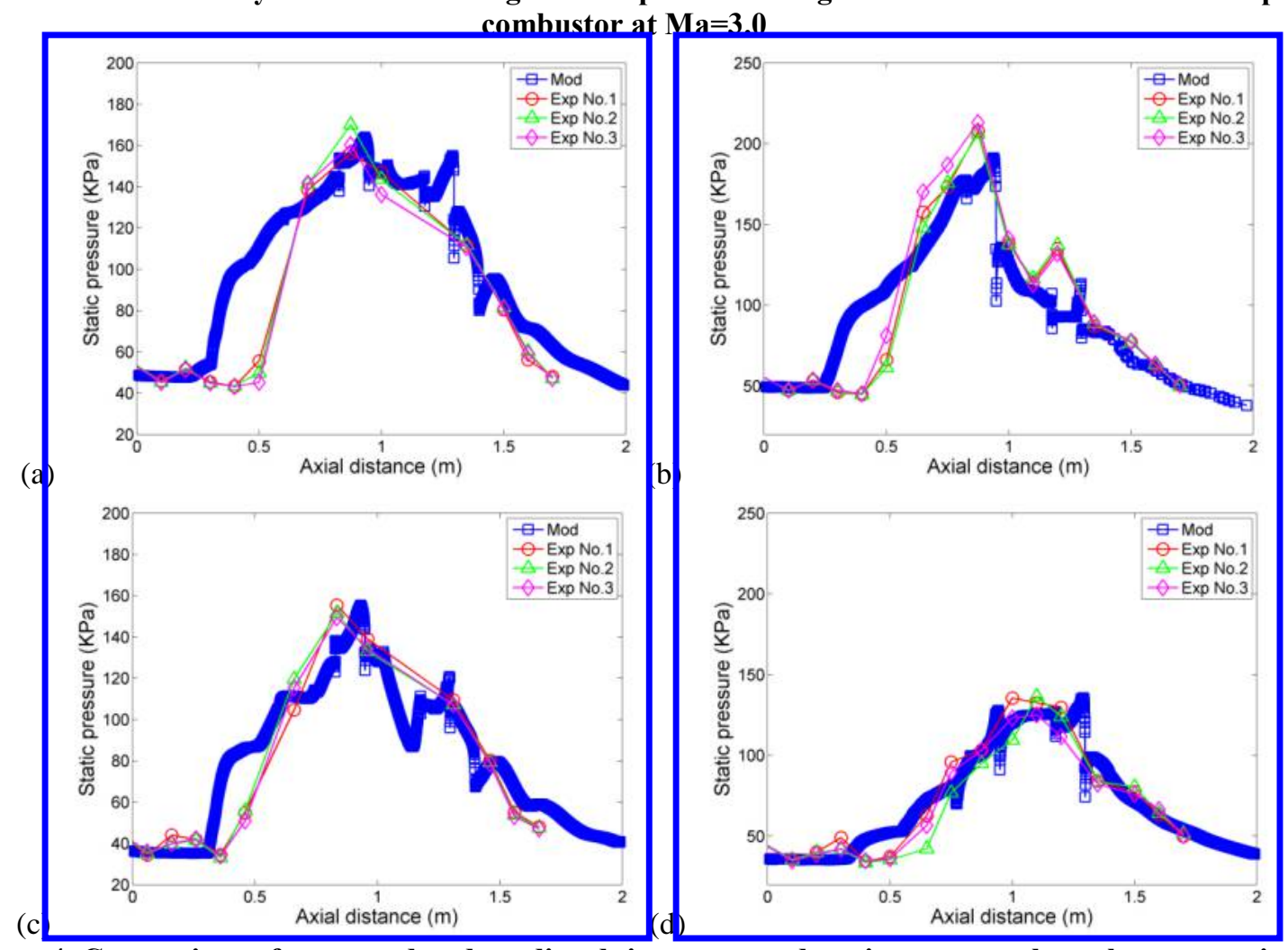

Figure 4. Comparison of measured and predicted time-averaged static pressure along the streamwise direction, (a) elliptic combustor at $M a=2.5$ (b) round combustor at $\mathrm{Ma}=2.5$ (c) elliptic combustor at $\mathrm{Ma}=3.0$ (d) round combustor at $M a=3.0$ 


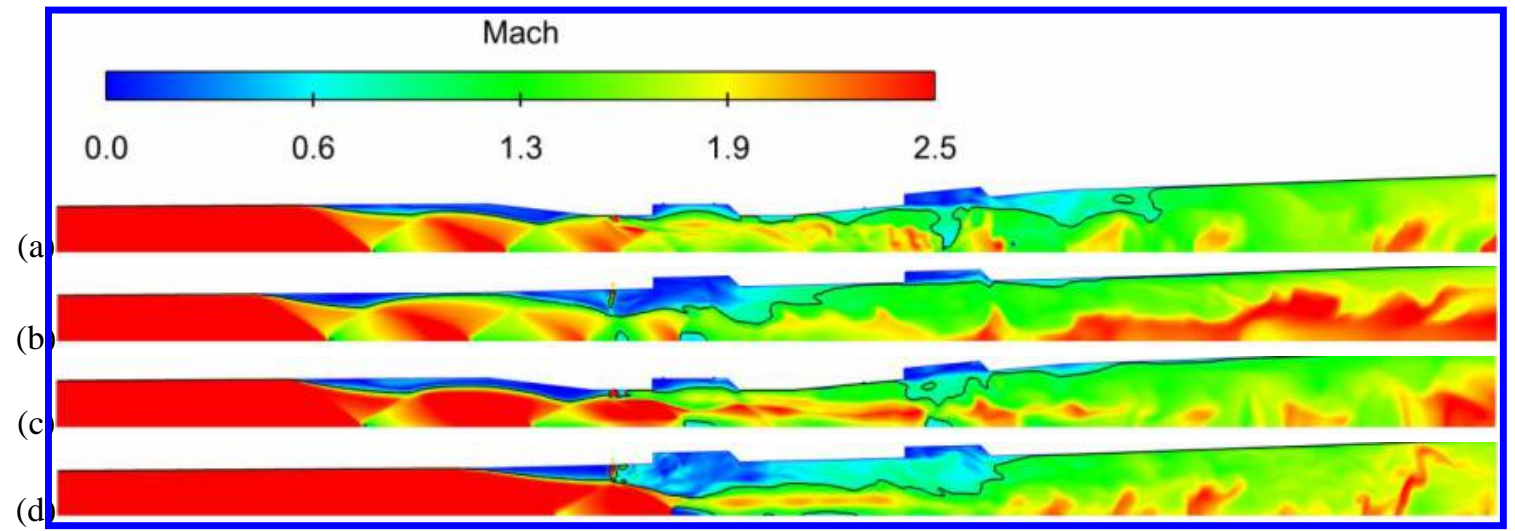

Figure 5. Instantaneous fields of Ma number on the clip planes through one injector, (a) elliptic combustor at $M a=2.5$, (b) round combustor at $M a=2.5$, (c) elliptic combustor at $M a=3.0$, (d) round combustor at $M a=3.0$; the black contour denotes sonic speed

From the static temperature distribution in Figure 6, one obvious observation is that the jet mixing is poor for the elliptic combustor cases, as the pure fuel jet is completely dispersed in a significantly longer downstream distance even reaching the downstream cavity. This can be explained by the shorter jet penetration depth, which causes an insufficient macro-mixing between the jet and the crossflow in the elliptic cases. For the round combustor cases, the mixing layer only extends slightly downstream the jet porthole and the jet is completely dispersed before the middle of upstream cavity. It can be concluded that the current elliptic combustor does not fulfill the initial design goal of increasing the jet mixing. However, one important advantage of elliptic combustor is that the shrinkage in elliptic burner section acts as an aerodynamic throat, which anchors the shock train in the isolator and provides a relatively steady crossflow conditions for the downstream combustion. This can be seen from the relative steady static pressure profiles in Figure 4 and the similar high-temperature region distribution as the crossflow Ma changes from 2.5 to 3.0 for the elliptic cases. However, for the round cases, as the crossflow Ma increases, the shock train moves significantly downstream, and the pressure rise ratio (in Figure 4) drops from 2.0 to 1.3 bar. A strong shock train consisting of multiple shock waves is in favor of the downstream combustion mainly by increasing temperature (to usually above $1200 \mathrm{~K}$ ), which can reduce the ignition delay by several orders of magnitudes as seen in Figure 1 (c) . At $\mathrm{Ma}=2.5$ the high temperature gas above $2000 \mathrm{~K}$ not only fills the whole upstream cavity but also propagates upstream to surround the jet root, indicating intense heat release occurs immediately after the jet issuing from its porthole. While at $\mathrm{Ma}=3.0$ the leading half part of upstream cavity has a relatively low-temperature $(<2000 \mathrm{~K})$, this is because those initial chain reactions corresponding to fuel pyrolysis are endothermic and the chemical time scale approximately equal to the ignition delay [69] increases orders of magnitudes at a relative low temperature. From the results, the upstream cavity act an important role of fuel-mixer and flame ignition, as high-temperature gas remains there all the way.

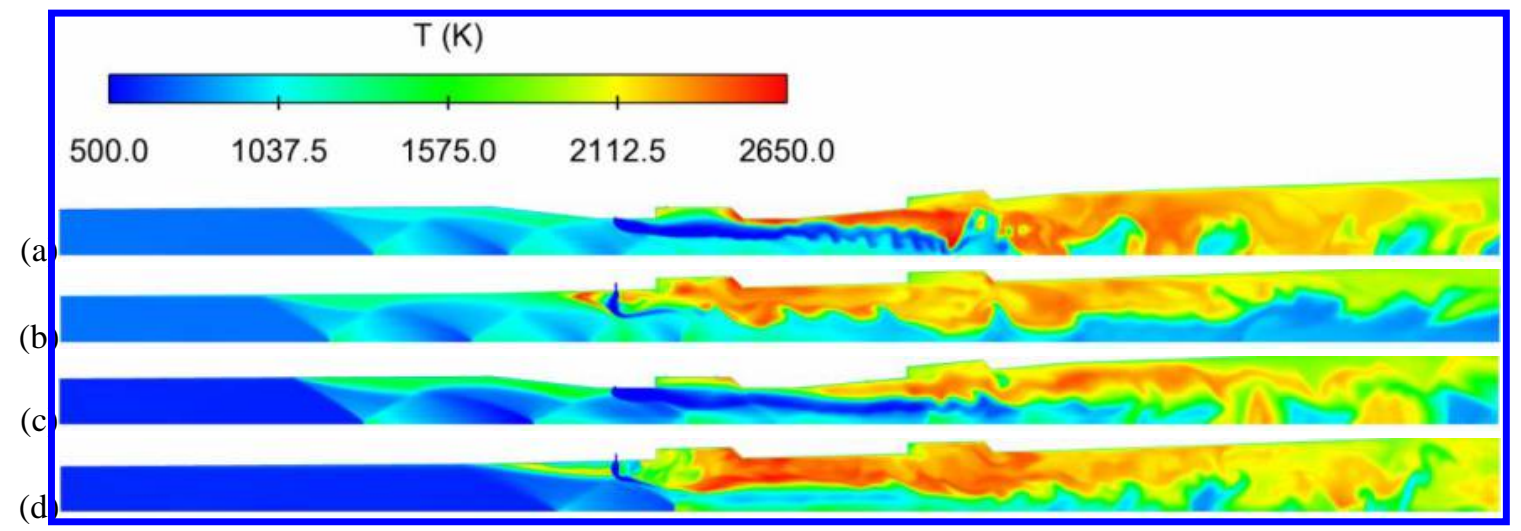

Figure 6. Instantaneous fields for static temperature on the clip planes through one injector, (a) elliptic combustor at $\mathrm{Ma}=\mathbf{2 . 5}$, (b) round combustor at $\mathrm{Ma}=2.5$, (c) elliptic combustor at $\mathrm{Ma}=3.0$, (d) round combustor at $M a=3.0$ 
Figure 7 shows the instantaneous numerical shadowgraph represented by the laplacian of density field, which clearly shows the structures of shock waves, high-density fuel stream and fire plume interfaces. The shock train consists of two shock waves except the round combustor case at Ma=3.0, where most of the shock train has been swallowed into the burner and only one shock wave is observed. At least two weaker shock waves reflected from the bow shock of supersonic jet can be observed for the elliptic cases. The penetration depth of fuel stream is confirmed to be lower and the unburnt fuel stream spreads longer in the downstream for the elliptic combustor cases than the round cases. The weaker shock waves intersect with the unburnt fuel stream, which is helpful for local fuel mixing through strengthening vortex generation [96,97]. The coherent fire plume interfaces in the expander section show obvious two-layer flow structures, i.e. the cold core flow beneath and the high-temperature combustion gas attached to the wall, as well as their entrainment.

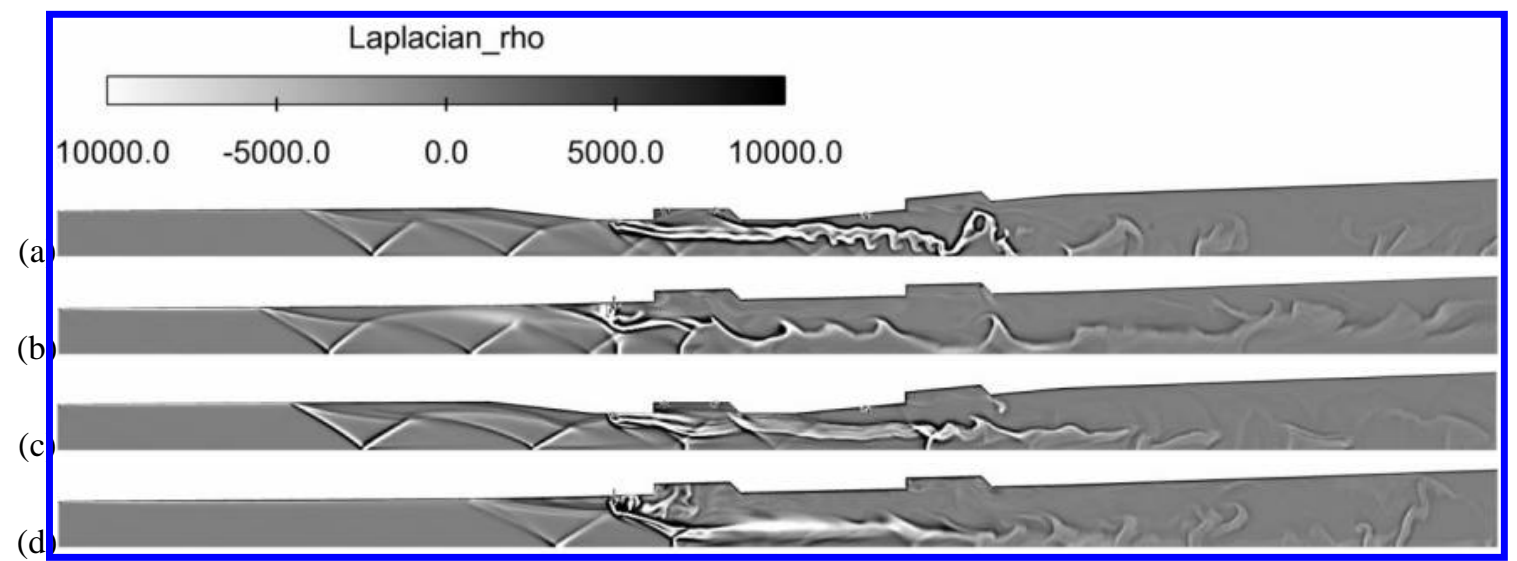

Figure 7. Instantaneous fields for numerical shadowgraph (laplacian of the density field) on the clip planes through one injector, (a) elliptic combustor at $\mathrm{Ma}=\mathbf{2 . 5}$, (b) round combustor at $\mathrm{Ma}=\mathbf{2 . 5}$, (c) elliptic combustor at $M a=3.0$, (d) round combustor at $M a=3.0$

Figure 8 shows the vorticity magnitude for the four combustor cases, which represents the generation source of vortexes. An obvious observation is that the boundary layer especially that detached in the isolator is the main generation of vortexes. Another important vortex inducing factor is the shear stress between the fuel stream and the core crossflow. The mixing layer above the downstream cavity also contributes greately to vortex generation. There is also strong vorticity magnitude in the shear layer covering the downstream cavity. The heat release by combustion reactions has two competing effects. One is decreasing the vorticity magnitude due to volume expansion through the dilatational term $-\vec{\omega}(\nabla \cdot \vec{u})(\vec{\omega}$ - vorticity, $\vec{u}$ - velocity). The other one is increasing the vorticity magnitude through the baroclinic term $\nabla T \times \nabla s$ ( $T$ - temperature, $s$ - enthropy), which is usually negligible in subsonic frozenchemistry flows but has the same order of magnitude with the dilatational term in supersonic flows [69]. Referring to Figure 6, the regions with intense heat release usually have more complex vorticity distribution than the colder $(<2000 \mathrm{~K})$ regions. For example, because the main combustion reactions occurs far downstream after the upstream cavity in the elliptic combustor cases, the vorticity distribution is not disturbed until there and is rather concentrated and highly coincided to the shear/mixing layers before there.

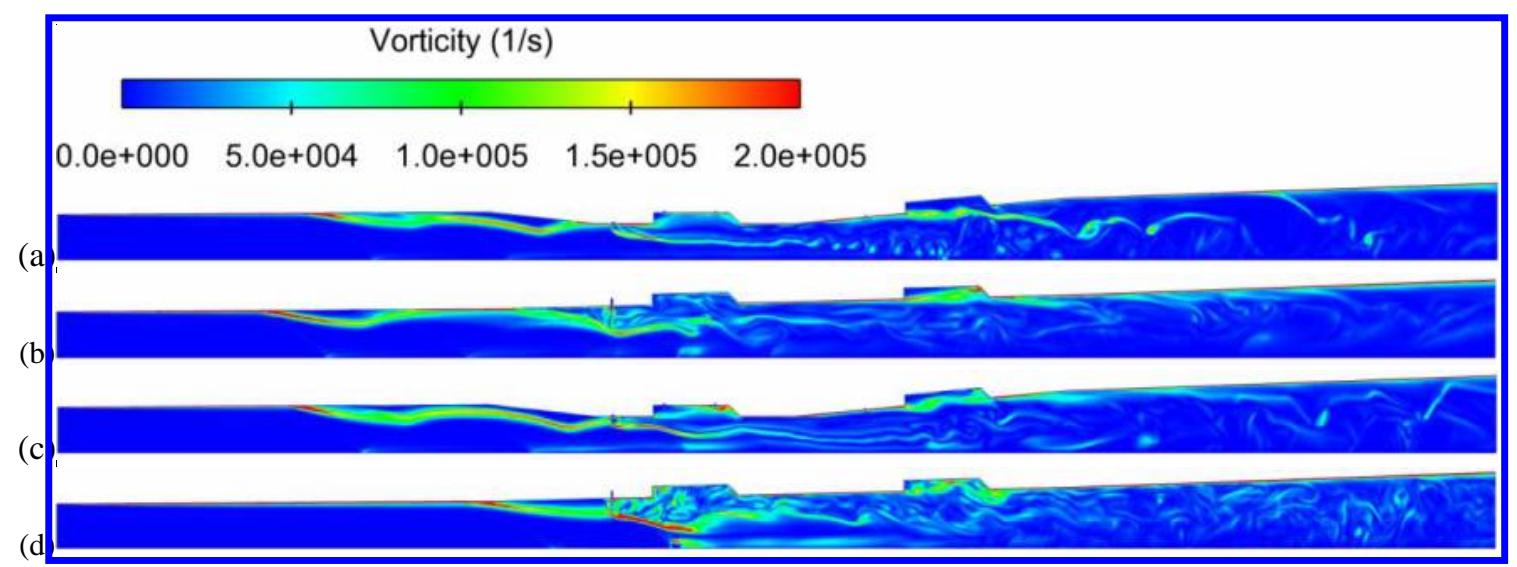

Figure 8. Instantaneous fields for vorticity on the clip planes through one injector, (a) elliptic combustor at 
$M a=2.5$, (b) round combustor at $M a=2.5$, (c) elliptic combustor at $M a=3.0$, (d) round combustor at $M a=3.0$

\section{B. Wave structures in elliptic combustor}

Due to the asymmetry of the elliptic cross-section, the wave structures may appear a unique spatial distribution. Figure 9 shows the three-dimensional wave structures in the elliptic combustor by aids of several intersected clip planes. Figure 9 (a) and (b) show that the oblique shock waves on the clip planes through the long and short axes of the elliptic cross-section are obviously similar in the round isolator section, but the shock waves deform differently in the two clip planes because the flow is expanding in the long axis plane but compressed in the short axis plane. The weak shock waves arising from the bow shock wave and their reflected waves are only observed in the short axis plane, since there is no jet injection on the long axis plane. But due to the volume expansion of the hot combustion gas layer, one strong oblique shock wave and its weak reflection via the shear layer can be observed in the core flow. Figure 9 (c) shows a close view of the main wave structures on the segment covering the isolator and burner sections. As seen, the waves in the shock train converge to one point on the axis, thus forming two pairs of funnel-shaped wave structures opposite to each other in the three-dimensional tube. The shock train is then enveloped by a drum-shape detached boundary layer in the neck region connecting the isolator and the burner. Figure 9 (d) shows the Ma contour delimited by the sonic speed line on the enlarged segment. As seen, all oblique shock waves produce supersonic regions after them, thus are classified as weak oblique shock waves. Two cone low-Ma regions corresponding to the funnel-shape waves can be clearly identified. The supersonic regions gradually shrink towards the core due to the volume expansion as the flow entering the burner section and then expands again in the expander section. It is also interesting to note that the supersonic core region varies irregularly in shape from one streamwise location to another in the burner section due to the jet penetration and heat addition

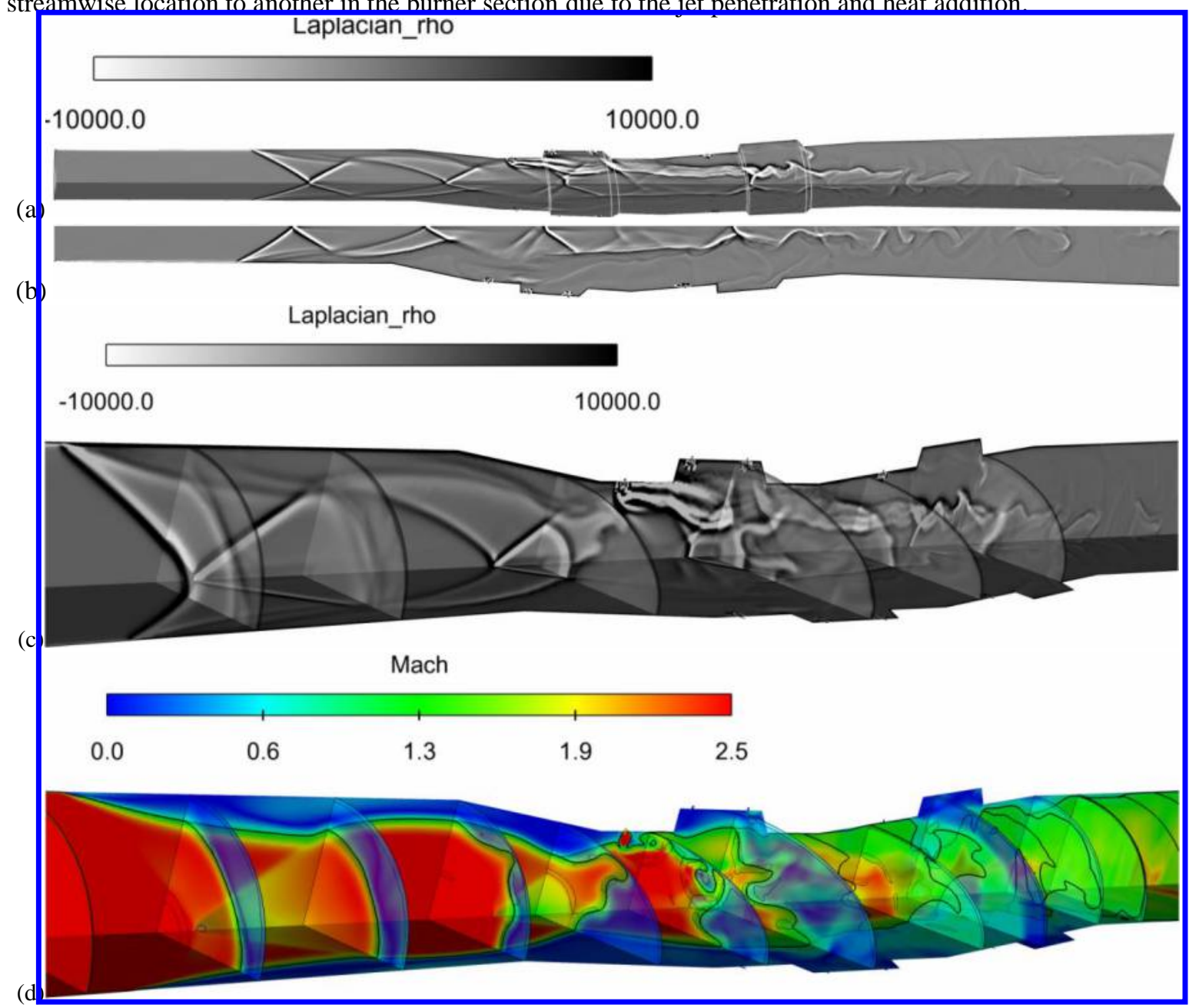

Figure 9. Numerical shadowgraph for the elliptic combustor at $\mathrm{Ma}=3.0$ (a) on intersected clip planes for the entire combustor, (b) on the clip plane through the long axis, and (c) on the enlarged segment covering the isolator and the burner; (d) Ma distribution on the enlarged segment, with the black line denotes sonic speed 


\section{Time evolution of wave and flame structures}

Figure 10 shows the Ma fields over a certain quasi-steady period. From the mean Ma distribution, the subsonic region mainly distributes in the upper layer of the burner section, while the flame Ma decreases as the aerodynamic throat shrinks and then increases in the expander section again. The flow Ma is extremely low in the two cavities and the backward-facing step (backstep) region immediately following the round-ellipse transition point. Those lowMa region should be favorable for fame anchoring since the flow residence time is longer and large-scale vortexes are produced in a similar manner as in the backstep problem. In the instantaneous fields, the subsonic region shrinks or expands considerably with a wave-like sonic interface. However, the initial position of shock train remains quite stable in a short distance before the transition point. Actually the shock train slides only slightly even under different crossflow Mach numbers, as shown in Figure 7. This suggests that the backstep effect when transiting from round to elliptic cross-section is favorable for the anchoring of shock train. The flow then seems to accelerate intermittently in the expander, exhibited as the intermittent distribution of high-Ma regions. This indicates that large-scale coherent structures exist there and thus the turbulent flow is far from isotropic even when approaching the combustor end.

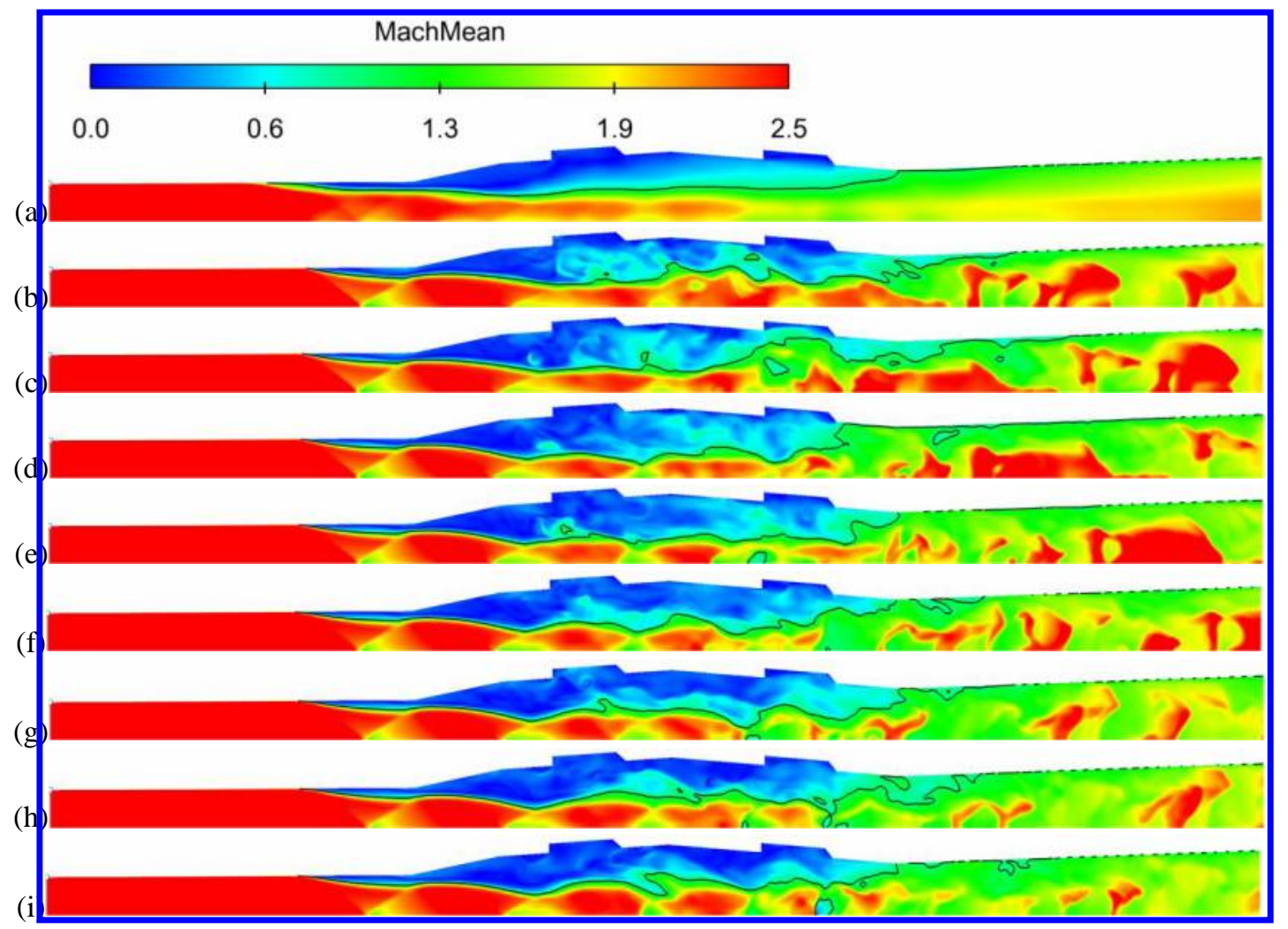

Figure 10. (a) Time-averaged and (b-i) consecutive instantaneous Ma fields with $0.1 \mathrm{~ms}$ intervals; the black contour denotes the sonic line $(\mathrm{Ma}=1)$

Figure 11 shows the time-averaged temperature field and time evolution of flame structures corresponding to the times in Figure 10. Although the flame structure transforms its shape all the time, the time-averaged temperature field shows that two constant flame anchoring regions are the shear layer extending from the transition point and the mixing layer around the downstream cavity. The shape transitions from round to ellipse at the upstream and from ellipse to round at the downstream form a backstep and a frontstep type flows, which can entrain oxygen from the crossflow through creating large-scale vortexes. The oxygen enrichment and the low-Ma are possibly the two main reasons for the flame anchoring there. Referring to Figure 10, at least part of the flame regions are located outside the subsonic region and combustion occurs under supersonic condition. From the instantaneous fields, the flame resides along the shear/mixing layer since the first shape transition point and then violent combustion occurs when approaching the next shape transition point. The convex elliptic section seems to act the role of a large open cavity. Much weaker combustion occurs in the bottom of the "cavity", possibly because the convex depth limits the transport of enough oxygen to there. Referring to Figure 6, the lengthy unburnt fuel stream sometimes penetrates 
laterally and observed as a small low-temperature spot in Figure 11 (c-f). The core crossflow in low temperature is gradually eroded by the expanding hot combustion layer in the burner section. The upper hot layer entrained with the core flow forming intermittent large-scale plume structures as the flow anproaching the combustor end

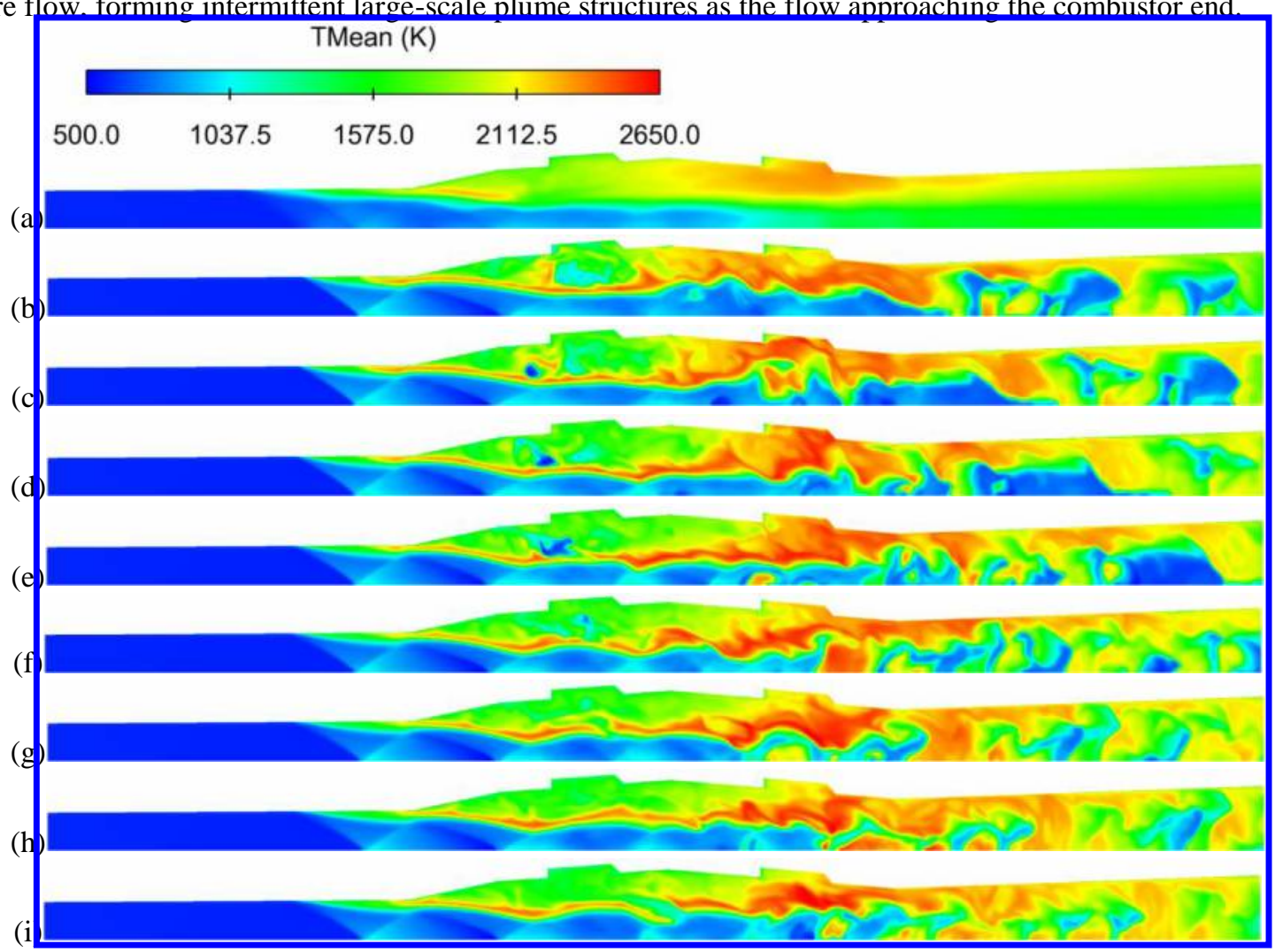

Figure 11. (a) Time-averaged and ( $h$-i) consecutive instantanenus tempera fure fields with $0.1 \mathrm{~ms}$ intervals

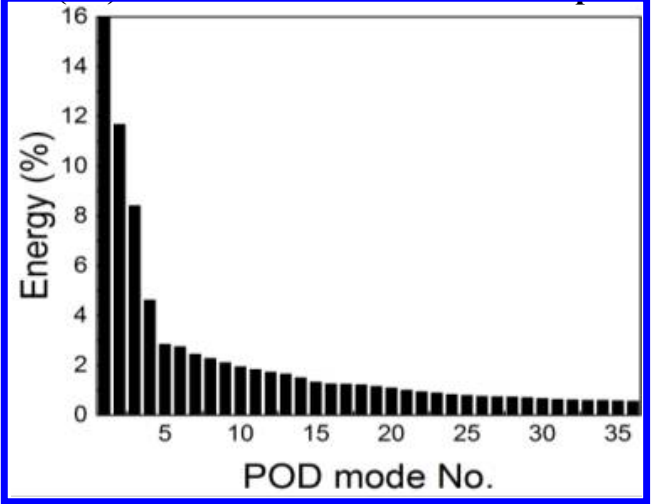

Figure 12. Relative energy of the first 36 POD modes

POD analysis is conducted for the time evolution of temperature fields over the quasi-steady period lasting $3 \mathrm{~ms}$ to reveal the dominant flame structure patterns. Figure 12 shows the relative energy percentage of the first 36 POD modes, where the first four modes have relative larger energy and are thus shown in Figure 13. Mode 1 and mode 2 are visually similar for the high-temperature strip region along the shear/mixing layer, which confirms the observation in Figure 11 that the main combustion reactions occur along the interface between the cold core flow and the hot upper layer. In mode 1, the after-shock regions also have relative high temperature. Also shown in mode 1, a thin hot layer attached to the upper wall while another high-temperature strip region distributes along the core flow in the expander, suggesting a clear stratification phenomenon there. Mode 3 and mode 4 present discontinuous flame regions in the front part of the burner section, and confirm the large attached flame region around the downstream cavity. The discontinuity indicates that the flame along the shear/mixing layer is possibly intermittent during the time evolution. Mode 4 presents a longer attached flame region even till the upstream cavity, implying 
that during a few time percentage flame also propagates upstream till there. Stratified high-temperature regions are also shown for the upper layer and beneath core flow respectively in mode 3 and 4 . From the 4 modes, the flame in the expander exhibits a clear oscillation pattern, which corresponds to a collection of vortexes due to entrainment of the two stratified lavers

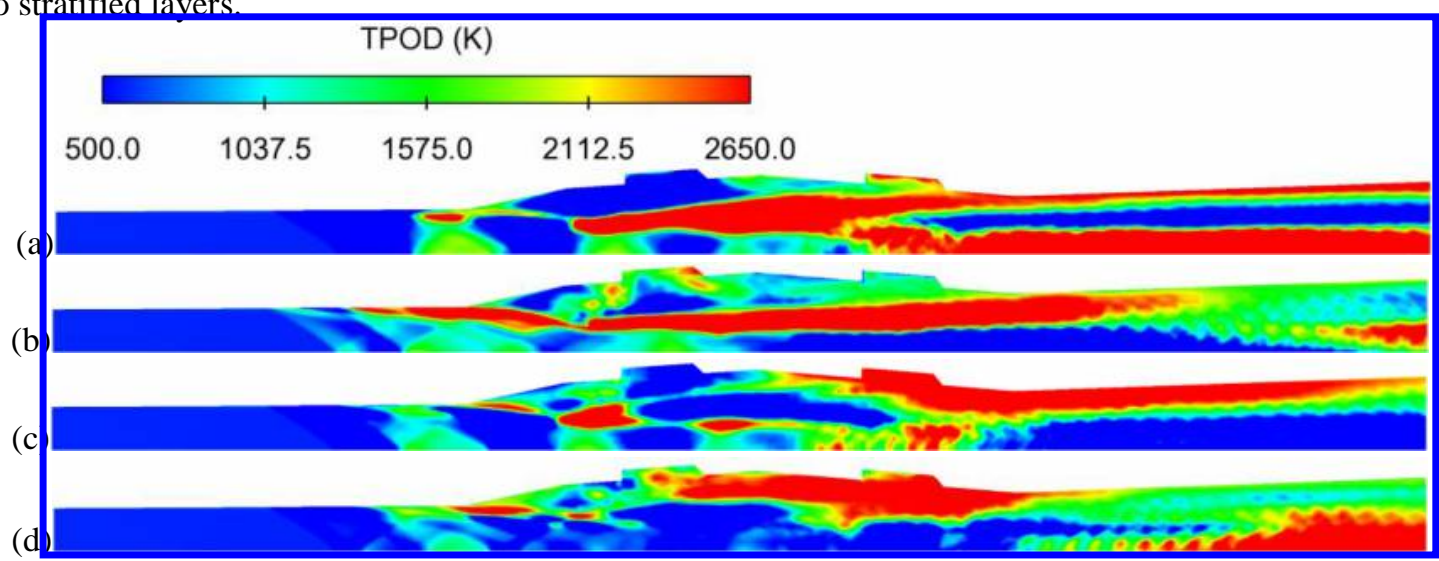

Figure 13. The first 4 POD modes, (a) mode 1, (b) mode 2, (c) mode 3, (d) mode 4

\section{Conclusions}

To explore the combustion performance of non-rectangular type supersonic combustors, the flow and combustion characteristics of round and round-to-elliptic shape-transition (RdEST) supersonic combustors under the same configuration of flight Ma (Mach number) and fuel equivalence ratio were compared based on modeling results. To alleviate the strict requirements on the near-wall mesh spacing, IDDES is employed in this study to enable an automatic choice of RANS or LES mode depending on the local boundary layer thickness and turbulent viscosity. Four cases with the same global fuel equivalence ratio of 0.8 but different inlet Mas of 2.5 and 3.0 for both the elliptic and round combustors are compared. The corresponding experimental tests of round and elliptic combustors are conducted in a continuous-flow supersonic combustion test facility, which simulates a real flight number of 6.5 using vitiated air crossflow. The modelings are based on a newly developed $19 \mathrm{~s} / 53 \mathrm{r}$ skeletal kerosene mechanism, which is even simpler than the previously used 28-species mechanism but agrees even better with the original 2185-species detailed mechanism in the main key kinetic properties, i.e. adiabatic flame temperature, heat release rate, ignition delay and laminar flame speed. Grid sensitivity analysis is conducted to assess the influence of global and local mesh resolutions on the pressure predictions. The modeling results were firstly validated against the measured static pressure, and overall good agreements are achieved using the current modeling framework. The main findings and conclusions are summarized as follows.

1) The predicted and measured time-averaged static pressure on the streamwise direction agree well for the two key aspects, i.e. the pressure ratio and the initial pressure rise location, indicating that the flame anchoring location and the distribution of wave structures inside the combustor are close to the actual situation. The continuous sonic line indicates that all the four combustor cases run in scramjet mode. The shown subsonic regions are obviously larger for round combustors. The initial location of shock train is insensitive to the inlet Ma for the elliptic combustor, but it slides downstream considerably and correspondingly the pressure rise ratio drops from 2.0 to 1.3 bar for the round combustor as Ma increases from 2.5 to 3.0. One important advantage of elliptic combustor is that the shrinkage in elliptic burner section acts as an aerodynamic throat, which anchors the shock train in the isolator and provides a relatively steady crossflow conditions for the downstream combustion. Thus the elliptic combustor is supposed to have better combustion stability. The shock train contains two shock waves except the round combustor case at $\mathrm{Ma}=3.0$, where most of the shock train has been swallowed into the burner and only one shock wave is observed. The observed jet penetration depth is lower and the jet mixing is poorer for the elliptic combustor cases. The detached boundary layer and the shear layer induce most of the vortexes responsible for downstream jet mixing.

2) The oblique shock waves on the clip planes through the long and short axes of the elliptic cross-section are obviously similar in the round isolator section, but the shock waves deform differently in the two clip planes because the flow is expanding in the long axis plane but compressing in the short axis plane. the waves in the shock train converge to one point on the axis, thus forming two pairs of funnel-shaped wave structures opposite to each other. The shock train is enveloped by a drum-shape detached boundary layer in the neck region connected the isolator and 
the burner. The supersonic region varies irregularly in shape from one streamwise location to another in the burner section.

3) In the instantaneous fields, the subsonic region shrinks or expands considerably with a wave-like sonic interface. However, the initial position of shock train remains quite stable in a short distance before the transition point. Actually the shock train slides only slightly even under different crossflow Mach numbers, suggesting that the backstep effect when transiting from round to elliptic cross-section is favorable for the anchoring of shock train. The shape transitions from round to ellipse at the upstream and from ellipse to round at the downstream form a backstep and a frontstep type flows, which anchor the flame through entraining oxygen and providing low-Ma bays. The convex elliptic section seems to act the role of a large open cavity. Much weaker combustion occurs in the upstream part of the "cavity", possibly because the convex depth limits the transport of enough oxygen to there. POD analysis confirms the main combustion reactions along the mixing interface, discontinuous flame regions in the front part of the burner section and a clear stratification phenomenon in the expander.

\section{Acknowledgments}

The Project was supported by National Natural Science Foundation of China (Grant No. 11502270) and Training Program of the Major Research Plan of the National Natural Science Foundation of China (Grant No. 91641110). The authors are also grateful to National Supercomputer Center in Tianjin for providing computational resource.

\section{References}

-1. Gollan, R., and Ferlemann, P. "Investigation of REST-class Hypersonic Inlet Designs", 17th AIAA International Space Planes and Hypersonic Systems and Technologies Conference. San Francisco, California, 2011, AIAA 2011-2254.

2. Luke, J. D., Michael, K. S., and David, M. "Measurement of Three-Components of Force on an Airframe Integrated Scramjet at Mach 10", 20th AIAA International Space Planes and Hypersonic Systems and Technologies Conference. AIAA 2015-3523, American Institute of Aeronautics and Astronautics, Glasgow,Scotland, 2015.

3. James, E. B., Dylan, J. W., Vincent, W., and Michael, K. S. "Tailored Fuel Injection for Performance Enhancement in a Mach 12 Scramjet Engine", 20th AIAA International Space Planes and Hypersonic Systems and Technologies Conference. AIAA 2015-3614, American Institute of Aeronautics and Astronautics, Glasgow, Scotland, 2015.

4. Dylan, J. W., and Michael, K. S. "Experimental Investigation of a Three-Dimensional Scramjet Engine at Mach 12", 20th AIAA International Space Planes and Hypersonic Systems and Technologies Conference. AIAA 2015-3650, American Institute of Aeronautics and Astronautics, Glasgow, Scotland, 2015.

-5. Doherty, L. J., Smart, M. K., and Mee, D. J. "Experimental Testing of an Airframe-Integrated ThreeDimensional Scramjet at Mach 10", AIAA Journal, 53 (11), 2015, 3196-3207.

-6. Barth, J. E., Wheatley, V., and Smart, M. K. "Effects of Hydrogen Fuel Injection in a Mach 12 Scramjet Inlet", AIAA Journal, 53 (10), 2015, 2907-2919.

-7. Suraweera, M. V., and Smart, M. K. "Shock-Tunnel Experiments with a Mach 12 Rectangular-to-Elliptic Shape-Transition Scramjet at Offdesign Conditions", Journal of Propulsion and Power, 25 (3), 2009, 555-564.

-8. Smart, M. K. "Experimental Testing of a Hypersonic Inlet with Rectangular-to-Elliptic Shape Transition", Journal of Propulsion and Power, 17 (2), 2001, 276-283.

-9. Billig, F. S. "Supersonic combustion ramjet missile", Journal of Propulsion and Power, 11 (6), 1995, 11391146.

10. Hartill, W. B. "Analytical and Experimental Investigation of a Scramjet Inlet of Quadriform Shape". Marquardt Corporation, 1965.

11. Gruber, M., Smith, S., and Mathur, T. "Experimental Characterization of Hydrocarbon-Fueled, Axisymmetric, Scramjet Combustor Flowpaths", 2011.

12. Smith, S., Gruber, M., Steiner, R., Collatz, M., and Mathur, T. "Development and Calibration of an Axisymmetric Direct-Connect Supersonic-Combustion Flowpath", 2009.

13. Smith, S., Gruber, M., Mathur, T., Tam, C.-J., Ryman, R., and Diemer, J. "Development of a Rotating Probe System for Supersonic Combustion Experiments", 2009.

14. David, P., Russell, B., and Vincent, W. "Hybrid Reynolds-Averaged and Large-Eddy Simulation of Mixing in an Axisymmetric Scramjet", 18th AIAA/3AF International Space Planes and Hypersonic Systems and 
Technologies Conference. AIAA 2012-5902, American Institute of Aeronautics and Astronautics, Tours, France, 2012.

15. Houshang, E., Datta, G., and Faure, M.-M. "Exploratory RANS and LES simulations of transient supersonic combustor flow", 47th AIAA Aerospace Sciences Meeting including The New Horizons Forum and Aerospace Exposition. American Institute of Aeronautics and Astronautics, 2009.

16. Yao, W., Li, X., Wu, K., and Fan, X. Detached Eddy Simulation of an axisymmetric scramjet combustor fueled by Daqing RP-3 aviation kerosene, The 8th National Conference on Hypersonic Science and Technology. Haerbing, 2015, CSTAM2015-A35-B0136.

17. Skare, P. E., and Krogstad, P.-a. "A turbulent equilibrium boundary layer near separation", Journal of Fluid Mechanics, 272, 1994, 319-348.

18. Mellor, G. L., and Gibson, D. M. "Equilibrium turbulent boundary layers", Journal of Fluid Mechanics, 24 (2), 1966, 225-253.

19. Speziale, C. "Turbulence Modeling for Time-Dependent RANS and VLES: A Review", AIAA Journal, 36 (2), 1998, 173-184.

20. Spaziale, C., and Spaziale, C. "Turbulence modeling for time-dependent RANS and VLES - A review", 13th Computational Fluid Dynamics Conference. Snowmass Village, Colombia, 1997, AIAA-97-2051.

21. Batten, P., Goldberg, U., and Chakravarthy, S. "Sub-grid turbulence modeling for unsteady flow with acoustic resonance". 2000.

22. Spalart, P. R., Jou, W. H., Strelets, M., and Allmaras, S. R. "Comments on the Feasibility of LES for Wings and a Hybrid RANS/LES Approach", First AFOSR Conference on DNS/LES. Ruston, Louisiana, 1997.

23. Su-Hee, W., In-Seuck, J., and Jeong-Yeol, C. "DES Investigation of the Ignition of Hydrogen Transverse Jet Into High Enthalpy Supersonic Crossflow", 47th AIAA Aerospace Sciences Meeting including The New Horizons Forum and Aerospace Exposition. AIAA 2009-1557, American Institute of Aeronautics and Astronautics, Orlando, Florida, 2009.

24. Peterson, D. M., Candler, G. V., and Drayna, T. W. "Detached Eddy Simulation of a Generic Scramjet Inlet and Combustor", 47th AIAA Aerospace Sciences Meeting Including The New Horizons Forum and Aerospace Exposition. AIAA 2009-130, Orlando, Florida, 2009.

-25. Won, S. H., In-Seuck, J., and Choi, J. Y. "DES Modeling of Supersonic Combustion in Scramjet Combustors", 42nd AIAA/ASME/SAE/ASEE Joint Propulsion Conference \& Exhibit. AIAA 2006-5097, American Institute of Aeronautics and Astronautics, Sacramento, California, 2006.

26. Su-Hee, W., In-Seuck, J., and Jeong-Yeol, C. "DES Study of Transverse Jet Injection into Supersonic Cross Flows", 44th AIAA Aerospace Sciences Meeting and Exhibit. AIAA 2006-1227, American Institute of Aeronautics and Astronautics, Reno, Nevada, 2006.

27. David, P., Pramod, S., and Graham, C. "DES Investigation of Transverse Injection into Supersonic Crossflow using a Hybrid Unstructured Solver", 44th AIAA Aerospace Sciences Meeting and Exhibit. AIAA 2006-903, American Institute of Aeronautics and Astronautics, Reno, Nevada, 2006.

28. Choi, J.-Y., Yang, V., Ma, F., Won, S.-H., and Jeung, I.-S. "DES combustion modeling of a scramjet combustor", 42nd AIAA/ASME/SAE/ASEE Joint Propulsion Conference \& Exhibit. AIAA 2006-5097, Sacramento, California, 2006.

-29. Spalart, P. R. "Detached-Eddy Simulation", Annual Review of Fluid Mechanics, 41 (1), 2009, 181-202.

-30. Spalart, P. R., and Allmaras, S. R. "A One-Equation Turbulence Model for Aerodynamic Flows", 30th Aeropsace Sciences Meeting \& Exhibit. AIAA-92-0439, Reno, Nevada, 1992.

31. Travin, A. K., Shur, M. L., Spalart, P. R., and Strelets, M. K. "Improvement of Delayed Detached-Eddy Simulation for LES with Wall Modelling", European Conference on Computational Fluid Dynamics. TU Delft, The Netherlands, 2006.

-32. Shur, M. L., Spalart, P. R., Strelets, M. K., and Travin, A. K. "A Hybrid RANS-LES Approach with DelayedDES and Wall-Modelled LES Capabilities", International Journal of Heat and Fluid Flow, 29, 2008, 16381649.

-33. Yao, W., Wang, J., Lu, Y., Li, X., and Fan, X. "Full-scale Detached Eddy Simulation of kerosene fueled scramjet combustor based on skeletal mechanism", 20th AIAA International Space Planes and Hypersonic Systems and Technologies Conference. Glasgow, Scotland, 2015, AIAA 2015-3579.

34. Yao, W., Wang, J., Lu, Y., and Fan, X. Skeletal mechanism generation based on DRGEPSA for Daqing RP-3 aviation kerosene and numerical validation, The 7th National Conference on Hypersonic Science and Technology. Huairou, Beijing, 2014, CSTAM2014-A62-B0044. 
35. Edward, S., Suhee, W., Cho, D. R., and Choi, J. Y. "Hybrid RANS/LES Study of Base-Bleed Flows in Supersonic Mainstream", 15th AIAA International Space Planes and Hypersonic Systems and Technologies Conference. AIAA 2008-2588, American Institute of Aeronautics and Astronautics, Dayton, Ohio, 2008.

-36. Lu, T., and Law, C. K. "Toward accommodating realistic fuel chemistry in large-scale computations", Progress in Energy and Combustion Science, 35 (2), 2009, 192-215.

-37. Fureby, C., Chapuis, M., Fedina, E., and Karl, S. "CFD analysis of the HyShot II scramjet combustor", Proceedings of the Combustion Institute, 33 (2), 2011, 2399-2405.

38. Larsson, J., Vicquelin, R., and Bermejo-Moreno, I. "Large eddy simulations of the HyShot II scramjet". Center for Turbulence Research, 2011, 63-74.

39. Cecere, D., Ingenito, A., Bruno, C., Giacomazzi, E., and Donato, F. "Advances in LES of the HyShot II Scramjet Combustor", Processes and Technologies for a Sustainable Energy. Ischia, 2010.

40. Antonella, I., Claudio, B., and Donato, C. "LES of the Hyshot Scramjet Combustor", 48th AIAA Aerospace Sciences Meeting Including the New Horizons Forum and Aerospace Exposition. AIAA 2010-758, American Institute of Aeronautics and Astronautics, Orlando, Florida, 2010.

41. Johan, L. "Large eddy simulation of the HyShot II scramjet combustor using a supersonic flamelet model", 48th AIAA/ASME/SAE/ASEE Joint Propulsion Conference \& Exhibit. AIAA 2012-4261, American Institute of Aeronautics and Astronautics, Atlanta, Georgia, 2012.

42. Romagnosi, L., Ingenito, A., Cecere, D., Giacomazzi, E., and Bruno, C. "The role of the baroclinic term in supersonic fuel/air mixing enhancement", 49th AIAA Aerospace Sciences Meeting including the New Horizons Forum and Aerospace Exposition. AIAA 2011-401, Orlando, Florida, 2011.

-43. Cecere, D., Ingenito, A., Giacomazzi, E., Romagnosi, L., and Bruno, C. "Hydrogen/air supersonic combustion for future hypersonic vehicles", International Journal of Hydrogen Energy, 36 (18), 2011, 11969-11984.

44. Cocks, P. A. T. "Large Eddy Simulation of Supersonic Combustion with Application to Scramjet Engines", Corpus Christi College. PHD, University of Cambridge, 2011.

45. Ingenito, A., and runo, C. B. "Mixing and combustion in supersonic reactive flows", 44th AIAA/ASME/SAE/ASEE Joint Propulsion Conference \& Exhibit. AIAA 2008-4574, Hartford, Connecticut, 2008.

-46. Ingenito, A., De Flora, M. G., and Bruno, C. "LES Modeling of Scramjet Combustion", 44th AIAA Aerospace Sciences Meeting and Exhibit. Reno, 2006.

47. David, P., and Graham, C. "Hybrid RANS/LES of a Supersonic Combustor", 26th AIAA Applied Aerodynamics Conference. AIAA 2008-6923, American Institute of Aeronautics and Astronautics, Honolulu, Hawaii, 2008.

48. David, P., Erik, T., and Graham, C. "Hybrid Reynolds-Averaged and Large-Eddy Simulation of Scramjet Fuel Injection", 17th AIAA International Space Planes and Hypersonic Systems and Technologies Conference. AIAA 2011-2344, American Institute of Aeronautics and Astronautics, San Francisco, California, 2011.

-49. Kim, S. H., Donde, P., Raman, V., Lin, K.-C., and Carter, C. "Large eddy simulation based Studies of Reacting and Non-reacting Transverse Jets in Supersonic Crossflow", 50th AIAA Aerospace Sciences Meeting including the New Horizons Forum and Aerospace Exposition. AIAA 2012-482, American Institute of Aeronautics and Astronautics, Nashville, Tennessee, 2012.

50. Jung, C., and Suresh, M. "Large-Eddy Simulation of Cavity-Stabilized Supersonic Combustion", 45th AIAA/ASME/SAE/ASEE Joint Propulsion Conference \& Exhibit. AIAA 2009-5383, American Institute of Aeronautics and Astronautics, Denver, Colorado, 2009.

51. Chaitanya, G., Jung, C., Srikant, S., and Suresh, M. "Large Eddy Simulation of Supersonic Combustion in a Cavity-Strut Flameholder", 49th AIAA Aerospace Sciences Meeting including the New Horizons Forum and Aerospace Exposition. AIAA 2011-323, American Institute of Aeronautics and Astronautics, Orlando, Florida, 2011.

52. Jung, C., Chaitanya, G., and Suresh, M. "Large-Eddy Simulation of Cavity Flame-Holding in a Mach 2.5 Cross Flow", 48th AIAA Aerospace Sciences Meeting Including the New Horizons Forum and Aerospace Exposition. AIAA 2010-414, American Institute of Aeronautics and Astronautics, Orlando, Florida, 2010.

-53. Sun, M.-b., Geng, H., Liang, J.-h., and Wang, Z.-g. "Mixing Characteristics in a Supersonic Combustor with Gaseous Fuel Injection Upstream of a Cavity Flameholder", Flow, Turbulence and Combustion, 82 (2), 2008, 271-286.

54. Man, Z., Zhiwei, H., Kai Hong, L., and Guoqiang, H. "LES of Kerosene Spray Combustion with Pilot Flame in a Model Dual Mode Ramjet Chamber", 45th AIAA/ASME/SAE/ASEE Joint Propulsion Conference \& Exhibit. AIAA 2009-5385, American Institute of Aeronautics and Astronautics, Denver, Colorado, 2009. 
-55. Liu, P., He, G., Hu, Z., and Zhang, M. "Large-eddy simulation of kerosene spray combustion in a model scramjet chamber", Proceedings of the Institution of Mechanical Engineers, Part G: Journal of Aerospace Engineering, 224 (9), 2010, 949-960.

-56. Kumaran, K., and Babu, V. "Mixing and Combustion Characteristics of Kerosene in a Model Supersonic Combustor", Journal of Propulsion and Power, 25 (3), 2009, 583-592.

-57. Kumaran, K., Behera, P. R., and Babu, V. "Numerical Investigation of the Supersonic Combustion of Kerosene in a Strut-Based Combustor", Journal of Propulsion and Power, 26 (5), 2010, 1084-1091.

-58. Hautman, D. J., Dryer, F. L., Schug, K. P., and Glassman, I. "A Multiple-step Overall Kinetic Mechanism for the Oxidation of Hydrocarbons", Combustion Science and Technology, 25 (5-6), 1981, 219-235.

-59. Westbrook, C. K., and Dryer, F. L. "Chemical kinetic modeling of hydrocarbon combustion", Progress in Energy and Combustion Science, 10 (1), 1984, 1-57.

60. Franzelli, B., Riber, E., Sanjosé, M., and Poinsot, T. "A two-step chemical scheme for kerosene-air premixed flames", Combustion and Flame, 157 (7), 2010, 1364-1373.

61. Choi, J.-Y. "A quasi global mechanism of kerosene combustion for propulsion applications", 47th AIAA/ASME/SAE/ASEE Joint Propulsion Conference \& Exhibit. AIAA 2011-5853, San Diego, California, 2011.

62. Dagaut, P., Karsenty, F., Dayma, G., Diévart, P., Hadj-Ali, K., Mzé-Ahmed, A., Braun-Unkhoff, M., Herzler, J., Kathrotia, T., Kick, T., Naumann, C., Riedel, U., and Thomas, L. "Experimental and detailed kinetic model for the oxidation of a Gas to Liquid (GtL) jet fuel", Combustion and Flame, 161 (3), 2014, 835-847.

63. Dagaut, P., and Cathonnet, M. "The ignition, oxidation, and combustion of kerosene: A review of experimental and kinetic modeling", Progress in Energy and Combustion Science, 32 (1), 2006, 48-92.

64. Dagaut, P. "On the kinetics of hydrocarbons oxidation from natural gas to kerosene and diesel fuel", Physical Chemistry Chemical Physics, 4 (11), 2002, 2079-2094.

65. Dagaut, P., Reuillon, M., Boettner, J.-C., and Cathonnet, M. "Kerosene combustion at pressures up to 40 atm: Experimental study and detailed chemical kinetic modeling", Symposium (International) on Combustion, 25 (1), 1994, 919-926.

66. Mawid, M. A., and Sekar, B. "Detailed Chemical Kinetic Modeling of JP-8/Jet-A Fuels Ignition in High Pressure Shock Tube", 42nd AIAA/ASME/SAE/ASEE Joint Propulsion Conference \& Exhibit. Sacramento, California, 2006, AIAA 2006-5102.

-67. Mzé-Ahmed, A., Dagaut, P., Hadj-Ali, K., Dayma, G., Kick, T., Herbst, J., Kathrotia, T., Braun-Unkhoff, M., Herzler, J., Naumann, C., and Riedel, U. "Oxidation of a Coal-to-Liquid Synthetic Jet Fuel: Experimental and Chemical Kinetic Modeling Study", Energy \& Fuels, 26 (10), 2012, 6070-6079.

68. Zeng, W., Liang, S., Li, H.-x., and Ma, H.-a. "Chemical kinetic simulation of kerosene combustion in an individual flame tube", Journal of Advanced Research, 2013.

-69. Yao, W., Lu, Y., Li, X., Wang, J., and Fan, X. "Improved Delayed Detached Eddy Simulation of a high-Ma active-cooled scramjet combustor based on skeletal kerosene mechanism", 52nd AIAA/SAE/ASEE Joint Propulsion Conference. Salt Lake City, Utah, 2016, AIAA-2016-4761.

70. Yao, W., Wang, J., Fan, E., Li, X., and Fan, X. IDDES study of the flow and combustion characteristics in a RP-3 fueled round-to-elliptic shape-transition supersonic combustor, The 9th National Conference on Hypersonic Science and Technology. Xi'an, China, 2016.

-71. Niemeyer, K. E., Sung, C.-J., and Raju, M. P. "Skeletal mechanism generation for surrogate fuels using directed relation graph with error propagation and sensitivity analysis", Combustion and Flame, 157 (9), 2010, 1760-1770.

72. Pope, S. B. "Computationally efficient implementation of combustion chemistry using in situ adaptive tabulation", Combustion Theory and Modeling, 1, 1997, 41-63.

-73. Yang, B., and Pope, S. B. "Treating chemistry in combustion with detailed mechanisms - In situ adaptive tabulation in principal directions - premixed combustion", Combustion and Flame, 112, 1998, 85-112.

-74. Lee, J. C., Najm, H. N., Lefantzi, S., Ray, J., Frenklach, M., Valorani, M., and Goussis, D. A. "A CSP and tabulation-based adaptive chemistry model", Combustion Theory and Modelling, 11 (1), 2007, 73-102.

-75. Singer, M. A., Pope, S. B., and Najm, H. N. "Operator-splitting with ISAT to model reacting flow with detailed chemistry", Combustion Theory and Modelling, 10 (2), 2006, 199-217.

-76. Chen, J.-Y., Blasco, J. A., Fueyo, N., and Dopazo, C. "An economical strategy for storage of chemical kinetics: Fitting in situ adaptive tabulation with artificial neural networks", Proceedings of the Combustion Institute, 28 (1), 2000, 115-121. 
77. Chen, J. Y. "Analysis of in Situ Adaptive Tabulation Performance for Combustion Chemistry and Improvement with a Modified Search Algorithm", Combustion Science and Technology, 176 (7), 2004, 11531169.

78. Baris, S., and Suresh, M. "Artificial Neural Networks Based Chemistry-Mixing Subgrid Model for LES", 47th AIAA Aerospace Sciences Meeting including The New Horizons Forum and Aerospace Exposition. AIAA 2009-241, American Institute of Aeronautics and Astronautics, Orlando, Florida, 2009.

79. Baris, S., and Suresh, M. "Representation of Chemical Kinetics by Artificial Neural Networks for Large Eddy Simulations", 43rd AIAA/ASME/SAE/ASEE Joint Propulsion Conference \& Exhibit. American Institute of Aeronautics and Astronautics, 2007.

80. Rajat, K., Vaidyanathan, S., and Suresh, M. "Towards Engineering Les of Reacting Flows:Artificial Neural Networks for Efficient Kinetics Modeling", 41st Aerospace Sciences Meeting and Exhibit. AIAA 2003-311, American Institute of Aeronautics and Astronautics, Reno, Nevada, 2003.

-81. Chen, J. Y., Blasco, J. A., Fueyo, N., and Dopazo, C. "An economical strategy for storage of chemical kinetics: Fitting in situ adaptive tabulation with artificial neural networks", Proceedings of the Combustion Institute, 28 (1), 2000, 115-121.

82. Spalding, D. B. "Mixing and chemical reaction in steady confined turbulent flames", Thirteenth symposium (International) on Combustion. 13, The Combustion Institute, 1971, 649-657.

-83. Magnussen, B. F., and Hjertager, B. H. "On mathematical modeling of turbulent combustion with special emphasis on soot formation and combustion", Proceedings of the Combustion Institute, 16, 1977, 719 719-729.

84. Magnussen, B. F. "On the Structure of Turbulence and a Generalized Eddy Dissipation Concept for Chemical Reaction in Turbulent Flow", 19th American Institute of Aeronautics and Astronautics Aerospace Science Meeting. St. Louis, Missouri, 1981.

85. Magnussen, B. F. "The Eddy Dissipation Concept: A Bridge Between Science and Technology", ECCOMAS Thematic Conference on Computational Combustion. Lisbon, Portugal, 2005.

86. Golovitchev, V. I., and jarnicki, R. "Numerical modeling of high temperature air "flameless" combustion", The 4th International Symposium on High Temperature Air Combustion and Gasification. Rome, Italy, 2001.

87. Golovitchev, V. I., Nordin, N., Jarnicki, R., and Chomiak, J. "3-D Diesel Spray Simulations Using a New Detailed Chemistry Turbulent Combustion Model", CEC/SAE Spring Fuels \& Lubricants Meeting \& Exposition. Paris, France, 2000.

88. John D. Anderson, J. "Inviscid high-temperature nonequilibrium flows", HYpersonic and high-temperature gas dynamics (2nd Edition). American Institute of Aeronautics and Astrinautics, Inc., Virginia, 2006.

89. OpenCFD Ltd. "OpenFOAM 3.0.1". http://www.openfoam.org/, 2015.

-90. Wu, K., Li, X., Yao, W., and Fan, X. "Three-Dimensional Numerical Study of the Acoustic Properties of a Highly Underexpanded Jet", 20th AIAA International Space Planes and Hypersonic Systems and Technologies Conference. AIAA 2015-3572, Glasgow, Scotland, 2015.

-91. Li, X., Wu, K., Yao, W., and Fan, X. "A Comparative Study of Highly Underexpanded Nitrogen and Hydrogen Jets Using Large Eddy Simulation", 20th AIAA International Space Planes and Hypersonic Systems and Technologies Conference. AIAA 2015-3573, Glasgow, Scotland, 2015.

92. Greenshields, C. J., Weller, H. G., Gasparini, L., and Reese, J. M. "Implementation of semi-discrete, nonstaggered central schemes in a colocated, polyhedral, finite volume framework, for high-speed viscous flows", International Journal for Numerical Methods in Fluids, 38 (2), 2009, 139-161.

93. Li, X., Yao, W., and Fan, X. "Large-Eddy Simulation of Time Evolution and Instability of Highly Underexpanded Sonic Jets", AIAA Journal, 54 (10), 2016, 3191-3211.

94. Fan, X., and Yu, G. "Analysis of thermophysical properties of Daqing RP-3 aviation kerosene", Journal of Propulsion Technology, 27 (2), 2006, 187-192.

95. Billig, F. S., Orth, R. C., and Lasky, M. "A Unified Analysis of Gaseous Jet Penetration", AIAA Journal, 9 (6), 1970, 1048-1058.

-96. Génin, F., and Menon, S. "Studies of shock/turbulent shear layer interaction using Large-Eddy Simulation", Computers \& Fluids, 39 (5), 2010, 800-819.

97. Liu, X., and Zhang, S. "Direct numerical simulation of the interaction of 2D shock wave and shear layer", Chinese Journal of Theoretical and Applied Mechanics, 45 (1), 2013, $62-75$. 